NBER WORKING PAPER SERIES

DIVIDEND INNOVATIONS AND

STOCK PRICE VOLATILITY

Kenneth D. West

Working Paper No. 1833

NATIONAL BUREAU OF ECONOMIC RESEARCH

1050 Massachusetts Avenue

Cambridge, MA 02138

February 1986

A previous version of this paper was circulated under the title "Speculative Bubbles in Stock Price Volatility." The research reported here is part of the NBER's research program in Economic Fluctuations. Any opinions expressed are those of the author and not those of the National Bureau of Economic Research. 
NBER Working Paper \#1833

February 1986

\section{Dividend Innovations and Stock Price Volatility}

\section{ABSTRACT}

This paper establishes an inequality that may be used to test the null hypothesis that a stock price equals the expected present discounted value of its dividend stream, with a constant discount rate. The inequality states that if this hypothesis is true, the variance of the innovation in the stock price is bounded above by a certain function of the variance in the innovation in the dividend. The bound is valid even if prices and dividends are nonstationary.

The inequality is used to test the null hypothesis, for some long term annual U.S. stock price data. The null is decisively rejected, with the stock price innovation variance exceeding its theoretical upper bound by a factor of as much as twenty. The rejection is highly significant statistically. Regression diagnostics and some informal analysis suggest that the results are more consistent with there being speculative bubbles in the U.S. stock market than with a failure of the rational expectations or constant discount rate hypothesis.

Kenneth D. West

Woodrow Wilson School

Princeton University

Princeton, I\$J 08544 
The source of fluctuations in stock prices has long been argued. Some observers have suggested that a major part of the fluctuations result from self fulfilling rumors about potential price fluctuations. In a famous passage, Keynes, for example, described the stock market as a certain type of beauty contest in which judges try to guess the winner of the contest: speculators devote their "intelligence to anticipating what average opinion expects average opinion to be" [15, p136]. An examination of practically any modern finance text (e.g., Brealey and Myers [5]) indicates that the economics profession tends to hold the opposite view. Stock price fluctuations are argued to result solely from changes in the expected present discounted value of dividends.

The subject has received increased attention in recent years because of the volatility tests of Leroy and Porter [21] and, especially, Shiller [33]. These tests seem to indicate that stock price fluctuations are too large to result solely from changes in the expected present discounted value (PDV) of dividends. There is, however, some question as to the validity of this conclusion. Marsh and Merton $[24,25]$ have objected to the tests' assumption that dividends are stationary around a time trend; Flavin [8] and Kleidon [20] have argued that in small samples the tests are biased toward finding excess volatility.

This paper develops and applies a stock market volatility test that is not subject to these criticisms. The test is based on an inequality on the variance of the innovation in the expected PDV of a given stock's dividend stream, and was first suggested by Blanchard and Watson [4].2 The inequality states that if discount rates are constant this variance is larger when expectations are conditional on just the set of current and past dividends than when expectations are conditional on a larger information set. It may be shown that this implies that the variance of the innovation in a stock price is 
bounded above by a certain function of the variance of the innovation in the corresponding dividend.

The paper checks whether the bound is satisfied by some long term annual data on the $S$ and $P 500$ and the Dow Jones indices. It is not. The estimated variance of the stock price innovation is about four to twenty times its theoretical upper bound. The violation of the inequality is in all cases highly statistically significant.

It is to be emphasized that the inequality is valid even when prices and dividends are integrated ARIMA process with infinite variances, and that the empirical work allows for such nonstationarity. In addition, the test procedure does not require calculation of a perfect foresight price; this price appears to be central to the small sample biases that are argued by Flavin [8] and Kleidon [20] to plague the Shiller [33] volatility test. The paper nonetheless performs a small Monte Carlo experiment to check whether under certain simple circumstances the small sample bias in this paper's test procedure could explain the results of the test. The answer is no.

While one of the purposes of this paper is to apply a volatility test with a relatively weak set of maintained statistical assumptions, that is not its only aim. It also considers the consistency of some of the test's maintained economic assumptions with the data, to help determine which among these should be relaxed, so that the excess price volatility might be explained. To that end, the paper uses a battery of formal diagnostic tests on the regressions that must be estimated to calculate the inequality. The test results are in general quite consistent with the test's maintained hypotheses of rational expectations and, perhaps suprisingly, of a constant rate for discounting future dividends. Some additional, less formal analysis, which considers further the constant discount rate hypothesis, does not suggest that the 
excessive price variability results solely from variation in discount rates. The test maintains essentially only one additional assumption, which is a transversality condition that puts an upper bound on expected growth in stock prices. If this condition is false, the excess volatility might be due to speculative bubbles of the sort considered by, for example, Blanchard and Watson $[4]$.

The evidence, then, is more consistent with a failure of the transversality condition than of the rational expectations or constant discount rate assumptions. The paper does not, however, attempt to make a detailed case for bubbles, or, for that matter, any other factor, as the explanation of the excess volatility. Instead what is emphasized are two empirical regularities that seem to characterize the data studied here. The first is that prices appear to be too variable to be set as the expected PDV of dividends, with a constant discount rate; this holds even if prices and dividends are nonstationary. The second is that a rational expectations, constant discount rate model appears to characterize these data remarkably well. Reconciliation of these two points is a task left for future research.

Before turning to the details of the subject at hand, a final introductory remark seems worth making. The inequality established here may be of general interest in that it could be used to test other infinite horizon present value models. Possible examples include testing whether consumption is too variable to be consistent with the permanent income hypothesis (a subject considered in Deaton [6]), or whether exchange rates are too variable to be consistent with a standard monetary model (West [40]). That the inequality is valid even in a nonstationary environment makes it particularly appealing in these and perhaps other contexts.

The plan of the paper is as follows. Section II establishes the basic 
inequality. Section III explains how the inequality may be used to test a rational expectations, constant discount rate stock price model. Section IV presents formal econometric results. Section $V$ considers informally whether small sample bias or discount rate variation are likely to explain the section IV results. Section VI has conclusions. An appendix has econometric details.

\section{The Basic Inequality}

The following proposition is the basis of this paper.

Proposition 1: Let $I_{t}$ be an information set consisting of the space spanned by the current and past values of a finite number of random variables. After suitable differencing, the random variables are assumed to be covariance stationary, and, without loss of generality, to have zero mean. Let $d_{t}$ be one of these variables. Let $H_{t}$ be a subset of $I_{t}$ consisting of the space spanned by current and past values of some subset of the variables in $I_{t}$ including at a minimum current and past values of $d_{t}$. Let $b$ be a positive constant, $0 \leqq b<1$. Define $x_{t}=\sum_{0}^{\infty} b_{d} d_{t+j}$. (The preceding and all other summations in this section run over $\left.j_{.}\right)$Suppose that $x_{t I}=E x_{t} \mid I_{t}$ and $x_{t H}=E x_{t} \mid H_{t}$ both exist. Then

$$
E\left(x_{t H}-E x_{t H} \mid H_{t-1}\right)^{2} \geq E\left(x_{t I}-E x_{t I} \mid I_{t-1}\right)^{2}
$$

Proof: 3 Write

$$
x_{t}=d_{t}+b x_{t+1}
$$

Project (2) onto $I_{t}$ to obtain

(3)

$$
\begin{aligned}
x_{t I} & =d_{t}+b E x_{t+1} \mid I_{t} \\
& =d_{t}+b x_{t+1, I}-b e_{t+1} \\
e_{t+1} & =x_{t+1, I}-E x_{t+1}\left|I_{t}=x_{t+1, I}-E x_{t+1, I}\right| I_{t}
\end{aligned}
$$


Recursive substitution for $x_{t+1, I}$, then for $x_{t+2, I}$, etc. yields

$$
x_{t I}=\sum_{0}^{\infty} b^{j} d_{t+j}-\sum_{1}^{\infty} b^{j} e_{t+j}=x_{t}-\sum_{1}^{\infty} b^{j} e_{t+j}
$$

By a similar argument, involving projections onto $\mathrm{H}_{t}$,

$$
\begin{aligned}
& x_{t H}=x_{t}-\sum_{1}^{\infty} b^{j} f_{t+j} \\
& f_{t+j}=x_{t+j, H}-E x_{t+j, H} \mid H_{t+j-1}
\end{aligned}
$$

Now, since $\operatorname{var}\left(x_{t}-x_{t I}\right)$ and $\operatorname{var}\left(x_{t}-x_{t H}\right)$ are finite (see below), we have

$$
\begin{aligned}
\operatorname{var}\left(x_{t}-x_{t H}\right) & =\operatorname{var}\left(x_{t}-x_{t I}+x_{t I}-x_{t H}\right)=\operatorname{var}\left(x_{t}-x_{t I}\right)+\operatorname{var}\left(x_{t I}-x_{t H}\right) \\
& \geq \operatorname{var}\left(x_{t}-x_{t I}\right)
\end{aligned}
$$

The second equality follows since $x_{t}-x_{t I}=x_{t}-E x_{t} \mid I_{t}$ is uncorrelated with anything in $I_{t}$, including, in particular, $x_{t I}-x_{t H}$. The assumptions of the proposition insure that $e_{t}$ and $f_{t}$ have zero mean, constant variance and are serially uncorrelated. So $\operatorname{var}\left(x_{t}-x_{t H}\right)=b^{2}\left(1-b^{2}\right)^{-1} E f_{t}^{2}$, $\operatorname{var}\left(x_{t}-x_{t I}\right)=b^{2}\left(1-b^{2}\right)^{-1} E e_{t}^{2}$, and (6) implies $E\left(x_{t H}-E x_{t H} \mid H_{t-1}\right)^{2} \geq$ $E\left(x_{t I}-E x_{t I} \mid I_{t-1}\right)^{2}$. Q.E.D.

A verbal restatement of Proposition 1 is as follows. Suppose we are forecasting the present discounted value of $d_{t}$, by calculating $x_{t I}$ and $x_{t H}$. Each period as new data become available we revise our forecast. $E\left(x_{t I}-E x_{t I} \mid I_{t-1}\right)^{2}$ and $E\left(x_{t H}-E x_{t H} \mid H_{t-1}\right)^{2}$ are measures of the average size of this period to period revision. Proposition 1 says that with less information the size of the revision tends to be larger. That is, when less information is 
used, the variance of the innovation in the expected present discounted value of $d_{t}$ is larger.

It is worth making four comments on the conditions under which (1) is valid. Further details on some of the comments may be found in footnote 4. First, (1) holds whenever $x_{t I}$ and $x_{t H}$ are well defined, as they will be if, for example, the variables in $I_{t}$ and $H_{t}$ follow a finite parameter ARIMA process. Note that this includes in particular processes with unit AR roots (an example is given below). Second, (1) does not extend immediately if logarithms or logarithmic differences are required to induce stationarity in $d_{t}$. If, for example, $\log \left(d_{t}\right)=\log \left(d_{t-1}\right)+\varepsilon_{t}, \quad \varepsilon_{t}-N\left(0, \sigma^{2}\right)$, it may be shown that $E\left(x_{t H}-E x_{t H} \mid H_{t-1}\right)^{2}$ does not even exist for $H_{t}=\left\{d_{t-j}\right\}$. Third, the inequality need not hold for a finite horizon. That is, it need not hold if we consider the variance of the innovation in the expected PDV of $\sum_{0}^{n} b^{j} d_{t+j}$ instead of $\sum_{0}^{\infty} b^{j} d_{t+j}$. Fourth, (1) does not hold for arbitrary subsets of $I_{t}$. If, for example, $H_{t}$ were the empty set, $x_{t H}$ would also be the empty set, and the left hand side of (1) would be identically zero. 4

Before developing the implications of (1) for stock price volatility, it may be helpful to work through a simple example. Suppose $I_{t}$ consists of lags of $d_{t}$ and of one other variable, $z_{t}$. Let $H_{t}$ consist simply of lags of $d_{t}$. Let the bivariate $\left(d_{t}, z_{t}\right)$ representation be

$$
\left[\begin{array}{l}
d_{t} \\
z_{t}
\end{array}\right]=\left[\begin{array}{ll}
\phi & 1 \\
0 & 0
\end{array}\right]\left[\begin{array}{l}
d_{t-1} \\
z_{t-1}
\end{array}\right]+\left[\begin{array}{l}
\varepsilon_{1 t} \\
\varepsilon_{2 t}
\end{array}\right]
$$

with $|\phi| \leq 1, \varepsilon_{1 t}$ and $\varepsilon_{2 t}$ i.i.d, $E \varepsilon_{1 t} \varepsilon_{2 s}=0$ for all $t, s$. Let $E \varepsilon_{1 t}^{2}=\sigma_{1}^{2}, E \varepsilon_{2 t}^{2}=\sigma_{2}^{2}$. The univariate representation of $d_{t}$ clearly is $d_{t}=\phi d_{t-1}+v_{t}$, $v_{t}=\varepsilon_{1 t}+z_{t-1}=\varepsilon_{1 t}+\varepsilon_{2 t-1}, E v_{t}^{2}=\sigma_{1}^{2}+\sigma_{2}^{2}$. Let us calculate both sides of (1). 
(8)

$$
\begin{aligned}
& E d_{t+j} \mid H_{t}=\phi^{j} d_{t} \\
\Rightarrow & x_{t H}=E \sum D^{j} d_{t+j} \mid H_{t}=(1-b \phi)^{-1} d_{t} \\
\Rightarrow & E\left(x_{t H}-E x_{t H} \mid H_{t-1}\right)^{2}=E\left[(1-b \phi)^{-1} v_{t}\right]^{2}=(1-b \phi)^{-2}\left(\sigma_{1}^{2}+\sigma_{2}^{2}\right) \\
& E d_{t} \mid I_{t}=d_{t} \\
& E d_{t+j} \mid I_{t}=\phi^{j} d_{t}+\phi{ }^{j-1} z_{t} \\
\Rightarrow & x_{t I} \equiv E_{0}^{\infty} b^{j} d_{t+j} \mid I_{t}=(1-b \phi)^{-1}\left(d_{t}+b z_{t}\right) \\
\Rightarrow & E\left(x_{t I}-E x_{t I} \mid I_{t-1}\right)^{2}=E\left[(1-b \phi)^{-1}\left(\varepsilon_{1 t}+b z_{t}\right)\right]^{2} \\
& \quad=(1-b \phi)^{-2}\left(\sigma_{1}^{2}+b^{2} \sigma_{2}^{2}\right)
\end{aligned}
$$

Since $b^{2}<1, \quad \sigma_{1}^{2}+\sigma_{2}^{2}>\sigma_{1}^{2}+b^{2} \sigma_{2}^{2}$, so (1) holds. Observe that (1) holds even when $\phi=1$ so that $d_{t}$ is nonstationary.

\section{III.The Model}

According to a standard efficient markets model, a stock price is determined by the arbitrage relationship (9) (Brealey and Myers [5, pp 42-45]):

$$
p_{t}=b E\left(p_{t+1}+d_{t+1}\right) \mid I_{t}
$$

where $p_{t}$ is the stock price at the end of period $t, b$ the constant ex-ante real discount rate, $0<b=1 /(1+r)<1, r$ the constant expected return, E denotes mathematical expectations, $d_{t+1}$ the real dividend paid to the owner of the stock in period $t+1$, and $I_{t}$ information common to traders in period $t$. $I_{t}$ is assumed to contain, at a minimum, current and past dividends, and, in general, other variables that are useful in forecasting dividends. Equation (9) may be solved recursively forward to get 


$$
p_{t}=\sum_{1}^{n} b^{j} E d_{t+j}\left|I_{t}+b^{n^{n} E p_{t+n}}\right| I_{t}
$$

If the transversality condition

$$
\lim _{n-->\infty} b^{n} E p_{t+n} \mid I_{t}=0
$$

holds, then

$$
\bar{p}_{t}=\sum_{1}^{\infty}{ }^{j} E_{t+j} \mid I_{t}
$$

Proposition 1 is used to test the model (12) as follows. Note first that since $x_{t I}=E_{0}^{\infty} b^{j} d_{t+j} \mid I_{t}$, (12) implies that $x_{t I}=p_{t}+d_{t}$. So $E\left(x_{t I}-E x_{t I} \mid I_{t-1}\right)^{2}=$ $E\left[p_{t}+d_{t}-E\left(p_{t}+d_{t} \mid I_{t-1}\right)\right]^{2}$, and, therefore,

$$
E\left(x_{t H}-E x_{t H} \mid H_{t-1}\right)^{2} \geq E\left[p_{t}+d_{t}-E\left(p_{t}+d_{t} \mid I_{t-1}\right)\right]^{2}
$$

The intuitive reason that the model (12) implies (13) is as follows. $E\left(x_{t H}-E x_{t H} \mid H_{t-1}\right)^{2}$ is by definition a measure of the average size of the innovation in the expected present discounted value (PDV) of dividends, when expectations are conditional on $H_{t}$. According to (12), price adjusts unexpectedly only in response to news about dividends. $E\left[p_{t}+d_{t}-E\left(p_{t}+d_{t} \mid I_{t-1}\right)\right]^{2}$ is a measure of the average size of the innovation in the expected PDV of dividends, with expectations conditional on the market's information set $I_{t}$. Since the market is presumed to use the variables in $I_{t}$ forecast optimally, the market's forecasts tend to be more precise, i.e., (13) holds. 5

To make (13) operational, both sides of it must be calculated. Consider 
first $E\left[p_{t}+d_{t}-E\left(p_{t}+d_{t} \mid I_{t-1}\right)\right]^{2}$. A consistent estimate of this is easily obtained by estimating ( 9 ) with the instrumental variables method of McCallum [26] and Hansen and Singleton [18]. Rewrite (9) as

$$
\begin{aligned}
p_{t} & =b\left(p_{t+1}+d_{t+1}\right)-b\left[p_{t+1}+d_{t+1}-E\left(p_{t+1}+d_{t+1} \mid I_{t}\right)\right] \\
& =b\left(p_{t+1}+d_{t+1}\right)+u_{t+1} \\
\sigma_{u}^{2} & =b{ }^{2} E\left[p_{t}+d_{t}-E\left(p_{t}+d_{t} \mid I_{t-1}\right)\right]^{2}
\end{aligned}
$$

Equation (14) can be estimated by instrumental variables, using as instruments variables known at time $t$. An estimate of $E\left[p_{t}+d_{t}-E\left(p_{t}+d_{t} \mid I_{t-1}\right)\right]^{2}$ is then obtainable as $\hat{b}^{-2} \hat{\sigma}_{u}^{2}$.

Estimation of $E\left(x_{t H}-E x_{t H} \mid H_{t-1}\right)^{2}$ is slightly more involved. It requires first of all specification of $H_{t}$. The simplest possible one is $H_{t}=\left\{1, d_{t-j} \mid j \geq 0\right\}$, and $H_{t}$ defined this way is what is used in this paper's empirical work. 6 Choices of $\mathrm{H}_{t}$ that include lags of additional variables might produce sharper results, but would also entail more complex calculations. With $H_{t}=\left\{1, d_{t-j}\right\}, E\left(x_{t H}-E x_{t H} \mid H_{t-1}\right)^{2}$ can be calculated as a function of $d_{t}{ }^{\prime} s$ univariate ARIMA parameters. Suppose $d_{t} \sim \operatorname{ARIMA}(q, s, 0)$

$$
\Delta^{s} d_{t+1}=\mu+\phi_{1} \Delta^{s} d_{t}+\ldots+\phi_{q} \Delta^{s} d_{t-q+1}+v_{t+1}
$$

where $\Delta^{S}=(1-L)^{S}$, L the lag operator. (A moving average component to $d_{t}$ is assumed absent for notational and computational simplicity.) Then $x_{t H}=E \sum b^{j} d_{t+j} \mid H_{t}=m+\sum_{1}^{q+s} \delta_{i} d_{t-i+1}$. The $\delta_{i}$ are complicated functions of $b$ and the $\phi_{i}$ - Hansen and Sargent [17] provide explicit formulas for the $\delta_{i}$. In particular, given $b$ and the ARIMA parameters of $d_{t}$, one can use the Hansen and Sargent [17] formula for $\delta_{1}$ to calculate $\delta_{1}^{2} \sigma_{v}^{2}=E\left(x_{t H}-E x_{t H} \mid H_{t-1}\right)^{2}$. To test the 
null hypothesis that prices are determined according to (12), then, we calculate

$$
\delta_{1}^{2} \sigma_{v}^{2}-b^{-2} \sigma_{u}^{2}
$$

and test $H_{0}: \delta_{1}^{2} \sigma_{v}^{2}-b^{-2} \sigma_{u}^{2} \geq 0$. If the estimate of (16) is negative (that is, the implications of (12) for the innovation variances are not borne out by the data), a convenient way to quantify the extent of the failure of the model (12) is to calculate

$$
-100\left(\delta_{1}^{2} \sigma_{v}^{2}-b^{-2} \sigma_{u}^{2}\right) /\left(b^{-2} \sigma_{u}^{2}\right)
$$

When (16) is negative, (17) yields a number between 0 and 100 . I will refer to this somewhat loosely as the percentage of the variance of the innovation in $p_{t}$ that is excessive. This is of course somewhat imprecise in that $b^{-2} \sigma_{u}^{2}$ is the variance of the innovation in the sum of dividends and prices. But given that price innovations are much larger than dividend innovations (see the empirical results below), this terminology does not seem misleading. 7

What alternatives might explain a rejection of the null hypothesis that (16) is positive? Three have figured prominently in discussions of related work: expectational irrationality (e.g., Ackley [1]), variation in discount rates (e.g., Leroy [22]) and speculative bubbles (e.g., Blanchard and Watson [4]). Elaboration of the relevant implications for asset price variability of the first two seems unnecessary since these are well known from the work of Shiller $[33,34,35]$. The speculative bubble alternative is perhaps less familiar, so some discussion seems warranted. 
Let us begin by noting that $p_{t}=E \sum b^{j} d_{t+j} \mid I_{t}$ is not the only solution to ( 1 ). If the transversality condition (11) fails, there is a family of solutions to (1) (Blanchard and Watson [4], Shiller [32], Taylor [36]). For any $c_{t}$ that satisfies $E c_{t}\left|I_{t-1}=b^{-1} c_{t-1}, p_{t}=E \sum b^{j} d_{t+j}\right| I_{t}+c_{t}$ is also a solution to (1). $c_{t}$ is by definition a speculative bubble, an otherwise extraneous event that affects stock prices because everyone expects it to do so. An example of a stochastic process for $c_{t}$, similar to one described in Blanchard and Watson [4], is

$$
c_{t}= \begin{cases}\left(c_{t-1}-\bar{c}\right) /\left(\pi_{t} b\right) & \text { with probability } \pi_{t} \\ \bar{c} /\left[\left(1-\pi_{t}\right) b\right] & \text { with probability } 1-\pi_{t} \\ 0<\pi_{t}<1, \bar{c}>0 & \end{cases}
$$

According to (18), strictly positive bubbles grow and pop. (See Blanchard and Watson [4] for an argument that negative bubbles are inconsistent with rationality.) In this example, the probability that a bubble grows is $\pi_{t}$, that it collapses is $1-\pi_{t}$. The bubble may reflect events like sunspots that have no connection with the expected present discounted value of dividends. $\pi_{t}$ might then be a random variable uncorrelated with anything in $I_{t}$. A more interesting possibility is that the bubble is intimately connected with fundamentals, with $\pi_{t}$ dependent on news about fundamentals. A simple example is $\pi_{t}=1 / 2$ for all $t$, with the bubble popping if and only if the innovation in dividends is negative. If $\pi_{t}$ is constant $\left(\pi_{t}=\pi\right.$ for all $\left.t\right)$, each bubble has an expected duration of $(1-\pi)^{-1}$. ( $\pi$ is not an identifiable parameter.) Combination of several bubbles are possible; the growth and collapse of the bubbles may be either tightly or loosely related. See Blanchard and Watson [4] for further examples and discussion.

Suppose that $p_{t}=E \sum b^{j} d_{t+j} \mid I_{t}+c_{t}$ for some bubble $c_{t}$ (possibly one not 
following the stochastic process (18)). Since $p_{t}+d_{t}=x_{t I}+c_{t}$, we have

$$
\begin{aligned}
E\left[p_{t}+d_{t}-E\left(p_{t}+d_{t} \mid I_{t-1}\right)\right]^{2}= & E\left(x_{t I}-E x_{t I} \mid I_{t-1}\right)^{2}+ \\
& 2 E\left(x_{t I}-E x_{t I} \mid I_{t-1}\right)\left(c_{t}-E c_{t} \mid I_{t-1}\right)+E\left(c_{t}-E c_{t} \mid I_{t-1}\right)^{2}
\end{aligned}
$$

When a bubble is present, the right hand side of (19) may be larger than $E\left(x_{t I}-E x_{t I} \mid I_{t-1}\right)^{2}$. It will unambiguously be larger if the innovation in the bubble is positively correlated with the innovation in $x_{t I}$. This will be the case if, for example, the bubble is connected with fundamentals and reflects a tendency of the market to overreact to news about dividends. This is sometimes argued to be plausible (e.g., Blanchard and Watson [4]).8

In the presence of bubbles, then, $b^{-2} \sigma_{u}^{2}$ will plausibly be bigger than $E\left(x_{t I}-E x_{t I} \mid I_{t-1}\right)^{2}$, and, therefore, (16) will be positive. In light of some empirical evidence yet to be presented, it is of particular interest to consider how to distinguish between bubbles on the one hand and expectational irrationality and time varying discount rates on the other as possible explanations of any excess price volatility. Formal econometric tests will help here. Consider, for example, diagnostic tests on the residual to equation (14). As long as (9) is correct--which it will be if expectations are rational and the discount rate is constant, even if there are bubbles-- $u_{t+1}$, the disturbance to $(14)$, is an expectational error. So $u_{t+1}$ should be serially uncorrelated and uncorrelated with anything in $I_{t}$, including, in particular, lagged dividends. But if expectations are not rational, $u_{t+1}$ will not in general have these properties. Nor will it if discount rates vary through time (see footnote 12).

Other diagnostics may also help distinguish between bubbles and other alternatives as possible explanations; some of these were calculated and are 
described in the next section. For the present, the important point to note is that when bubbles are absent, the arbitrage equation (14) and the dividend equation (15) together imply that (16) is positive. The only apparent form of misspecification that leaves (14) and (15) legitimate, but is still consistent with (16) being negative, is speculative bubbles. So an essential part of the strategy used here to distinguish between bubbles and other alternatives as explanations of excessive price variability is to perform diagnostic tests on equations (14) and (15). If these appear to be well specified, a logical inference is that bubbles explain the excess volatility. 9

Such an inference may of course be incorrect. There may be small sample biases in the diagnostic tests. In addition, one may have a strong theoretical presumption that speculative bubbles are not present, or that the basic model has been misspecified in that, say, discount rates vary through time: it is certainly true that a consensus view on how general are the equilibria that admit bubbles is far from established, and that intertemporal asset pricing theories suggest that discount rates vary in general. 10 It would then be reasonable to give little credence to formal econometric evidence based on asymptotic distributions.

It is beyond the scope of this paper to consider these points in great detail. Section $V$ does, however, analyze informally some of them. 


\section{Empirical Results.}

A. Data and Estimation Technique.

The data used were those used by Shiller [33] in his study of stock price volatility, and were graciously supplied by him. There were two data sets, both containing annual aggregate price and dividend data. One had the Standard and Poor 500 for 1871-1980 $\left(\mathrm{p}_{t}=\right.$ price in January divided by producer price index $(1979=100), d_{t+1}=$ sum of dividends from that same January to the following December, deflated by the average of that year's producer price index). The other data set was a modified Dow Jones index, 1928-1978 $\left(p_{t}, d_{t+1}\right.$ as above). See Shiller [33] for a discussion of the data.

The following aspects of estimation are discussed in turn:

(i) selection of the dividend process's lag length $q$, (ii) estimation of (14), (15) and (16), (iii) calculation of the variance-covariance matrix of the parameters estimated, and (iv) diagnostic tests performed. (i) It was assumed that the univariate $d_{t}$ process required at most one difference to induce stationarity. That is, in equation (15), $s=0$ (the original series used) or $s=1$ (first difference of original series used). No other values of $s$ were tried.

For both the differenced and undifferenced versions of each data set's dividend process, two values of lag length $q$ were used. One was arbitrarily selected as $q=4$. The other was the $q$ selected by the information criterion of Hannan and Quinn [14]. This criterion chooses the value of $q$ that minimizes a certain function of the estimated parameters, and asymptotically chooses the correct $q$ if the process truly has a finite order autoregressive representation. 11 
Thus, for each data set up to four sets of parameter estimates were calculated: $q=4, q=l a g$ length selected by the information criterion, for differenced and undifferenced series. In one case (Dow Jones, differenced), the Hannan and Quinn [14] criterion chose $q=4$. So only three sets of parameters were calculated for Dow Jones.

(ii) Calculation of (16) required estimation of the bivariate system consisting equations (14) and (15). Equation (14) was estimated by Hansen's [15] and Hansen and Singleton's [18] two-step two-stage least squares. The first step was standard two stage least squares. The second step obtained the optimal instrumental variables estimator. The $q^{+1}$ instruments used were the variables on the right hand side of (15), i.e., a constant term and $q$ lags of $\Delta^{s} d_{t} \quad(s=0$ or $s=1)$. Equation (15) was estimated by OLS, with the covariance matrix of the parameter estimates adjusted for conditional heteroscedasticity as described in (iii).

With $\Delta^{S} d_{t} \sim \operatorname{AR}(q)$, the $\delta_{1}$ parameter in equation

(16) is $[(1-b) \stackrel{s}{ } \Phi(b)]^{-1}, \phi(b)=1-\sum_{1}^{q} b^{i} \phi_{i}$, (Hansen and Sargent [17]).

Thus, equation (16) was calculated as $\left[(1-\hat{b}) s\left(1-\sum_{i=1}^{q} \hat{b}^{i} \hat{\phi}_{i}\right)\right]^{-2 \hat{\sigma}} \hat{\sigma}_{v}^{2}-\hat{b}^{-2} \hat{\sigma}_{u}^{2}$.

$\hat{\sigma}_{u}^{2}$ and $\hat{\sigma}_{v}^{2}$ were calculated from the moments of the residuals of the regressions with a degrees of freedom correction used for $\hat{\sigma}_{v}^{2}$ : 


$$
\begin{aligned}
& \hat{\sigma}_{u}^{2}=(T-s)^{-1} \sum_{t=1}^{T-s} \hat{u}_{t+1}^{2} \\
& \hat{\sigma}_{v}^{2}=(T-s-q-1)^{-1} \sum_{t=1}^{T-s} \hat{v}_{t+1}^{2} .
\end{aligned}
$$

$\mathrm{T}$ is the number of observations, $\mathrm{T}=110$ for the Standard and Poor's index, $T=51$ for the Dow Jones index.

The parameter vector estimated was thus $\hat{\theta}=\left(\hat{b}_{, \mu_{1}}, \hat{\phi}_{1}, \ldots, \hat{\phi}_{q}, \hat{\sigma}_{u}^{2}, \hat{\sigma}_{v}^{2}\right)$. $\hat{\theta}$ is asymptotically normal with an asymptotic covariance $V$ (see the appendix and (iii) below). Let $f(\theta)$ be equation (16) above. The standard error on the estimate of equation (16) was calculated as $\left[(\partial f / \partial \theta) V(\partial f / \partial \theta)^{\prime}\right]^{1 / 2}$ (See Rao $\left.[29, p p .385-86].\right)$ The derivatives of $f$ were calculated analytically. (iii) The estimate of $\mathrm{V}$, the variance-covariance matrix of $\hat{\theta}$, was calculated by the methods of Hansen [15] and White and Domowitz [42] so that the estimate would be consistent for an arbitrary ARMA process for $u_{t}$ and $v_{t}$. This is necessary because, for example, the correlation between $u_{t}$ and $v_{t+j}$ may in principle be nonzero for all $j \geq 0$. The Newey and West [27] procedure was used to insure that $V$ was positive definite. Details may be found in the appendix. It suffices to note here that the procedure for calculating the standard error on (16) properly accounts for the uncertainty in the estimates of both the regression parameters and the variances of the residuals. (iv) The final item discussed before results are presented is diagnostic tests on equations (14) and (15). Four diagnostic checks were performed. 
The first checked for serial correlation in the residuals to the equations, using a pair of tests. As noted above, $u_{t+1}$, the disturbance to equation (14), is an expectational error. If expectations are rational, then, $u_{t+1}$ will be serially uncorrelated. Equation (15)'s disturbance $v_{t+1}$ should also be serially uncorrelated, since $v_{t+1}$ is the innovation to the dividend process.

The first of the pair of serial correlation tests checked for first order serial correlation in $u_{t+1}$ and $v_{t+1}$. This was done as suggested in Pagan and Hall [28, pp. 191, 170]. The second of the pair of serial correlation tests, performed only for (15), calculated the Box-Pierce Q statistic for the residuals. This statistic of course simultaneously tests for first and higher order serial correlation, see Granger and Newbold [10, p. 93].

The second of the four diagnostic checks was performed only on equation (14). This was a test of instrument-residual orthogonality, basically checking whether the residual to (14) is uncorrelated with lagged dividends (Hansen and Singleton [18]). Let $z_{t}$ be the $((q+1) \times 1)$ vector of instruments and $\hat{b}$ the estimate of $b$. The orthogonality test is computed as:

$$
\left(\sum_{t=1}^{T-s} z_{t}^{\prime}\left[p_{t}-\hat{b}\left(p_{t+1}+d_{t+1}\right)\right]\right)\left(\hat{T S}_{z}\right)^{-1}\left(\sum_{t=1}^{T-s} z_{t}\left[p_{t}-\hat{b}\left(p_{t+1}+d_{t+1}\right)\right]\right)
$$

$\hat{S}_{z}$ is an estimate of $E\left(Z_{t} u_{t+1}\right)\left(Z_{t} u_{t+1}\right)^{\prime}$ and was calculated as $T^{-1}\left(\Sigma Z_{t} Z_{t}^{\prime} \tilde{u}_{t+1}^{2}\right)$,

$\tilde{u}_{t}$ the 2 sLS residual to (14). The statistic (21) is asymptotically distributed as a chi-squared random variable with $q$ degrees of freedom. As explained in a footnote, this test in general has the power to detect 
failures of the model (12) such as expectational irrationality and variation in discount rates. 12

The third of the four diagnostic checks tested for the stability of the regression coefficients in (14) and (15). Each sample was split in half, a pair of regression estimates was obtained, and equality of the pair was tested. The resulting statistic is asymptotically chi-squared, with one degree of freedom for (14) and $(q+1)$ degrees of freedom for (15). This test clearly has the power to detect shifts in the discount rate, as well as in the dividend process.

The fourth and final diagnostic check performed is implicit in the estimation procedure described above. A variety of specifications for the dividend process were used--differenced and undifferenced, with a variety of $\mathrm{lag}$ lengths. Since the results did not prove sensitive to the specification of the dividend process, the likelihood is relatively small that changes in the specification of the dividend process will affect the results.

\section{B. Empirical Results.}

Regression results for (14) and (15) are reported in Tables IA and IB. The results in Table IA strongly suggest that the basic arbitrage equation (1) is a sensible one. The entries in column (4) allow comfortable acceptance of the null hypothesis of no serial correlation in $u_{t+1}$, the disturbance to equation (14). The test statistic in all cases is far from significant at the .05 level. In addition, the equation (19) test for instrument-residual orthogonality also allows easy acceptance of the null hypothesis of no correlation between the instruments and the residuals. A possible exception is the Standard and Poor's data set, 
undifferenced, lag length $=2$. See column (5). The generally successful results in column (5) are perhaps especially noteworthy since failures of rational expectations models to pass this test are quite common (e.g., Hansen and Singleton [18], West [38]).

Most important, the discount rate $b$ is estimated plausibly and extremely precisely in all regressions. See column (3). The implied annual real interest rates are about six to seven per cent. These rates are quite near the arithmetic means for ex post returns: 8.1 percent for the Standard and Poor's index (1872-1981) and 7.4 per cent for the Dow Jones index (1929-1979). The estimates of the discount rate therefore are reasonable. The plausibility of the estimates of the discount rate provide special reassurance that the specification of the arbitrage equation (1) is an attractive one, since rational expectations models often fail to estimate ex ante real rates either sensibly or precisely (e.g., Blanchard [3], Rotemberg [30], Sargent [31]). Moreover, there is little evidence that the rate was different in the two halves of either sample. As indicated in column (6), the null hypothesis of equality cannot be rejected at the five per cent level for any specification except Standard and Poor's, undifferenced, $q=2$. In addition, no evidence against the constancy of the discount rate may be found in a comparison of the two halves' mean ex post returns. For the Standard and Poor's index, these were (in per cent) 8.09 (1872-1926) versus $8.12(1927-1981)$; for the Dow Jones the figures are $7.87(1929-1954)$ versus 6.92 (1955-1979).

In general, then, the specification of the arbitrage equation (14) seems quite attractive, with the possible exception of the Standard and Poor's data set with dividends undifferenced. Let us now turn to the 
estimates for the dividend process, reported in Table IB. Once again, the entries in columns (8) and (9) allow comfortable acceptance of the null hypothesis of no serial correlation in the disturbance to equation (15). With one exception, both test statistics in all regressions are far from significant. The only exception was the estimate of the first order serial correlation coefficient $\hat{\rho}$ for the Standard and Poor's index, undifferenced, lag length $q=2$. Note, however, that this regression's $Q$ statistic in column (9) comfortably accepts the null hypothesis of no serial correlation. Overall, then, no serial correlation to the residual to (15) is apparent. Also, the estimates of most regression coefficients are fairly precise, at least when the lag length $q$ was chosen by the Hannan and Quinn [14] procedure. Finally, the null hypothesis that the parameters of the dividend process are the same in the two halves of each sample cannot be rejected for any specification except the Standard and Poor's, undifferenced. See column (10). Overall, then, the specification of the dividend process seems quite acceptable, again with the possible exception of the Standard and Poor's data set, undifferenced.

The null hypothesis that price is the expected present discounted value of dividends, with a constant discount rate, does not, however, appear acceptable, for any specification. As may be seen from column (7) in Table II, equation (16) was always negative, and significantly so. The asymptotic z-stat (ratio of parameter to asymptotic standard error) was always larger than 2.5. This means that the column (7) entries are always significant at the one-half per cent level, using a one-tailed test. The null hypothesis may therefore be rejected at traditional significance levels. Furthermore, the fraction of the variance of the 
price innovation that is excessive is substantial, about 80 to 95 percent (column (8) of Table II).

The residual price fluctuation might reflect irrational reaction to news about dividends, variation in discount rates, or some combination of these and other factors. For the $S$ and $P$ undifferenced specifications, the econometric evidence is not particularly helpful in discriminating among these possibilities. It is worth noting, however, that for the other specifications, the results of the diagnostic tests were more consistent with the residual volatility being due to speculative bubbles than to a misspecification of the arbitrage or dividend equations. 13 


\section{V.Some Additional Analysis}

This section considers the possibilities that the previous section's results are due to (A) small sample bias, or (B)variation in discount rates. It is to be emphasized that the analysis is informal, and the conclusions are far from definitive. The goal here is simply to gather some evidence on whether either possibility explains the results; a complete, rigorous econometric examination of either possibility would require a separate paper.

\section{(A) Small Sample Bias}

This section uses two small Monte Carlo experiments to get a feel for the importance of two types of bias. Part (1) below considers whether under certain simple circumstances small sample bias is likely to account for the finding of excess variability. Part (2) studies whether under equally simple circumstances low small sample power of the equation (21) test of instrument residual volatility is likely to explain the generally favorable results of the diagnostic tests.

(1) It is important to consider whether small sample bias explains the finding of excess variability, in light of the evidence in Kleidon [20] and Marsh and Merton [25] suggesting that if prices and dividends are nonstationary, the Shiller [33] variance bounds test is strongly biased towards finding excess variability. To see whether there is a similar bias in the present paper's test, an environment similar to that in Kleidon [20] and Marsh and Merton [25] was assumed. A Monte Carlo experiment was performed, assuming: (a)dividends follow a random walk, $\Delta d_{t}=\mu+v_{t}$, and (b) $H_{t}=I_{t}$, so that equations (16) and (17) are zero.

In this experiment, $\mu$ and $\sigma_{V}^{2}$ were matched to the $S$ and $P$ sample values of the mean and variance of $\Delta d_{t}, \mu=.0373, \sigma_{v}^{2}=.1574$. b was set to .9413 , the value estimated in line 2 of Table IA. For each of 1000 samples, the following was 
done: A vector of 100 independent normal shocks was drawn, $\left(v_{1}, \ldots, v_{100}\right)$. Dividends and prices were calculated as $\Delta d_{t}=.0373+v_{t} ; d_{t}=d_{0}+\sum \Delta d_{s}\left(d_{0}=1.3\right)$; $p_{t}=\Sigma(.9413){ }^{j} E d_{t+j} \mid I_{t}=m+\delta_{1} d_{t}, m=(.0373) *(.9413) /(1-.9413), \delta_{1}=.9413 /(1-.9413)$. $\hat{\mu}$ and $\hat{\sigma}_{v}^{2}$ were then estimated by an OLS regression of $\Delta d_{t}$ on a constant, $\hat{b}$ and $\hat{\sigma}_{u}^{2}$ by an instrumental variables regression of equation (14), with a constant as the only instrument. Finally, equation (17), the percentage of price variability that is excessive, was calculated from the estimated parameters.

Table IIIA presents the empirical distribution of equation (17). Ideally, the median value of this statistic would be zero, with half the samples yielding a positive value to (17). Instead it is 15.0, and about two thirds of the samples produced a positive value. So there is a bias towards a finding of excess variability. The bias is not, however, particularly marked, and fewer than 10 percent of the simulated regressions produced the extreme values of the sort found in all of the Table II specifications.

That the Table IIIA distribution is only slightly biased suggests more strongly than might be immediately apparent that small sample bias does not explain the Table II results. For Table IIIA contains worst case figures, since it is based on simulations in which $H_{t}=I_{t}$. Proposition 1 implies that for any $g i$ ven $b$ and univariate $\Delta d_{t}$ process, $\sigma_{u}^{2}$ will be smaller when $I_{t}$ contains additional variables useful in forecasting $d_{t}$ than when $I_{t}=H_{t}$. This suggests that when $I_{t}$ contains these variables estimates of $\sigma_{u}^{2}$ and of equation (17) will be smaller as well. But a simulation with such variables in $I_{t}$ does not seem worth undertaking, because even under worst case circumstances assumed here, there is little to suggest that small sample bias explains the excess variability reported in Table II. (2) It is possible that the diagnostic tests reported basically favorable results because the tests have low power. It is particularly difficult to 
consider this comprehensively, even if only one of the diagnostic tests is analyzed. This is because Monte Carlo experiments here are potentially quite burdensome computationally. This will be true if $p_{t}$ or $d_{t}$ are generated nonlinearly under the alternative, as will be the case, for example, in most formulations of the Lucas [23] asset pricing model.

So this section has a relatively modest aim, of using a single diagnostic test and a single, simple form of misspecfication, to suggest whether the data and sample size are such that the diagnostic tests are unlikely to detect plausible misspecifications. The test that is used is the equation (21) test of instrument residual orthogonality. The misspecification that is assumed is that expectations are static rather than rational, $E d_{t+j} \mid I_{t}=d_{t}$. In such a case, the disturbance to the arbitrage equation (14) is $-b\left(\Delta p_{t+1}+\Delta d_{t+1}\right)$. So the test must pick up a correlation between $\Delta p_{t+1}+\Delta d_{t+1}$ on the one hand and lagged $\Delta d_{t}$ (the instruments, assuming a differenced specification) on the other. That the results of a simulation for this alternative might produce representative results is perhaps suggested by the fact that for just about any alternative, the residual is some function, possibly nonlinear, of expected and/or actual prices, dividends, and possibly, other variables. (See footnote 12.) So to have power against plausible alternatives, the test will basically have to be able to pick up a correlation between prices and dividends on the one hand and lagged $\Delta d_{t}$ on the other, and, again, this is exactly what it must do to have power against the static expectations alternative.

Under this alternative, $p_{t}=[b /(1-b)] d_{t} ; b=.9413$ was again assumed. Dividends were assumed to be generated by an $\operatorname{ARIMA}(2,1,0)$ process, with the parameters given by line (2) of Table IB. The following was done 1000 times. A vector of 100 independent normal disturbances was generated, with the variance of the disturbances equal to that reported in line (2), column (6) of 
Table II. One hundred $\Delta d_{t}{ }^{\prime} s$, and then one hundred $d_{t}{ }^{\prime} s$ and $p_{t}{ }^{\prime} s$, were computed, with initial conditions matching the initial values of the $S$ and $P$ $\left(\Delta d_{-1}=.16, \Delta d_{0}=11, d_{0}=1.61\right) . \hat{b}$ was then estimated by two step, 2SLS, with a constant, $\Delta d_{t}$, and $\Delta d_{t-1}$ as instruments. Finally, the equation (21) statistic was calculated.

The distribution of this statistic, which is a $x^{2}(2)$ random variable under the null, is reported in Table IIIB. In about fourth fifths of the cases, the statistic was above 5.99, the ninety five per cent level for a $x^{2}(2)$ random variable. In over nine tenths of the cases, the statistic was over 2.87 , the value reported in line (2), column (5), in Table IA.

Against this alternative, then, the test of instrument residual orthogonality appears to have reasonable power. Whether this applies to other alternatives or to the other diagnostic tests performed is uncertain. But the limited amount of evidence presented here at any rate does not suggest that the favorable results of the diagnostic tests result solely from low power of the tests.

\section{B.Variation in discount rates}

One possible explanation for the excess variability found in section IV is that discount rates are time varying, so that the error in equation (14). reflects not only news about dividends but also about discount rates (or, equivalently, expected returns). The diagnostic tests performed in section IV do not seem to suggest such variation, and the section VA(2) analysis just completed does not seem to indicate that the results of these tests are easily dismissed. Further consideration of the plausibility of this variation as an explanation seems warranted nonetheless, given theoretical work such as Lucas [23] and empirical evidence such as in Shiller [35].

This will be done in two separate exercises. The first (part (1) below) 
assumes as in, e.8., Hansen and Singleton [18], that a consumption based asset pricing model determines expected returns, with the representative consumer's utility function displaying constant relative risk aversion. For small values of the coefficient of relative risk aversion, this permits exact calculation of equation (17), the percentage excess variability. The second (part (2) below) does not model expected returns parametrically but instead uses Shiller's [33] linearized version of a completely general model. This permits calculation of a lower bound to how large a standard deviation in expected returns is required to explain the excess variability reported in Table II.

(1) Consider the class of models (e.g., Hansen and Singleton [18]) in which the first order condition for the return on a stock is $E\left\{B\left(C_{t+1} / C_{t}\right)^{-\alpha}\left[\left(p_{t+1}+d_{t+1}\right) / p_{t}\right]\right\} \mid I_{t}=1$, where $B, \quad \alpha<B<1$, is the representative consumer's subjective discount rate, $C_{t}$ is his real consumption, a his coefficient of relative risk aversion, with $E, d_{t}, p_{t}$ and $I_{t}$ defined as above. This may be rearranged as

$$
\begin{aligned}
\tilde{p}_{t}= & \beta E\left(\tilde{p}_{t+1}+\tilde{d}_{t+1}\right) \mid I_{t} \\
& \tilde{p}_{t}=p_{t} c_{t}^{-\alpha}, \tilde{d}_{t}=d_{t} c_{t}^{-\alpha}
\end{aligned}
$$

Equation (22) is of the same form as equation (9). So if $\tilde{d}_{t}$ is stationary, perhaps after one or more differences are taken, the statistics computed in the constant discount rate case can be computed in this model as well. 13 Repetition of the entire procedure is beyond the scope of this paper (and, in light of the results about to be presented, seems pointless). Instead, I will focus on obtaining a point estimate of equation (17), the percentage excess variability, for various imposed values of $\beta$ and $\alpha$.

The $c_{t}$ variable used in these calculations was the Grossman and Shiller 
[11] annual figure on real, per capita consumption of nondurables and services, 1889-1978. $\tilde{d}_{t}$ and $\tilde{p}_{t}$ were calculated using the $S$ and $P$ data for various values of $\alpha$. A simple plot of $\tilde{d}_{t}$ suggested that $\tilde{d}_{t}$ in neither levels nor first or higher differences is stationary for a much bigger than one. The problem is that for big $\alpha, \tilde{d}_{t}$ displays a marked secular decline; this is unsuprising given that annual $C_{t}$ growth was nearly 2 per cent per year, $d_{t}$ growth slightly above one per cent.

I nonetheless calculated (17), the percentage excess variability, for a wide range of $\alpha$, just in case $\tilde{d}_{t}$ really is stationary for large $\alpha$. This was done for $B=.95$ and $B=.98$, with very similar results. In all cases the lag length of the $\tilde{d}_{t}$ autoregression was set to four. Table IVA contains the figures that resulted for some of the $\alpha$, with $\beta=.98$. As may be seen, there is no evidence supporting the hypothesis that the excess variability displayed in Table II is explained solely by the sort of variation in expected returns predicted by this asset pricing model. 15

Since $\tilde{d}_{t}$ does not appear stationary for $\alpha$ much bigger than unity, it is equally true that Table IVA contains no evidence against the hypothesis that the Table II excess variability is explained by variation in expected returns associated with a coefficient of risk aversion greater than, say, one. Table IVA does, however, suggest if the model of expected returns assumed here is correct, that the Table II excess variability is unlikely to be due to variation in expected returns associated with a coefficient of relative risk aversion of less than, say, one.

(2) Let us now consider a general model that does not parameterize expected returns, linearized as in shiller [33] to make the analysis tractable. Let $r_{t+j}$ be the one period return expected by the market at period $t+j$, assumed covariance stationary. Suppose $p_{t}=E\left\{\sum_{j=1}^{\infty}\left[i_{i=1}^{j}\left(1+r_{t+i-1}\right)^{-1}\right] d_{t+j}\right\} \mid I_{t}$. Let us 
linearize the quantity in braces around $\bar{r}$ and $\bar{d} . \bar{r}$ is the mean of $r_{t}$; selection of $\bar{d}$ is discussed below. Define $b=(1+\bar{r})^{-1}, a=-\bar{d} / \bar{r}$. Then (Shiller

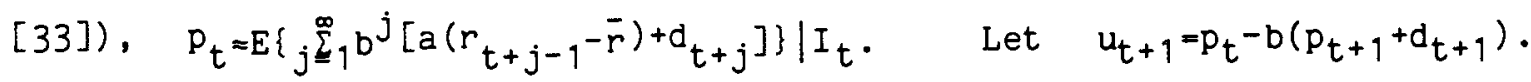
Proposition 1 may be used to show that in this linearized model

$$
\delta_{1}^{2} \sigma_{v}^{2}-b^{-2} \sigma_{u}^{2} \geq-\left[a^{2}+\left(1-b^{2}\right)^{-1} a^{2}\right] \sigma_{r}^{2}-\left[2\left(1-b^{2}\right)^{-1 / 2} a \delta_{1} \sigma_{v}\right] \sigma_{r}
$$

where $\sigma_{r}$ is the standard deviation of $r_{t}$, and $\delta_{1}$ and $\sigma_{v}$ are as defined in equation (16). The algebra to derive (23) is in a footnote. ${ }^{16}$

The left hand side of (23) is precisely the quantity studied in sections III and IV. If this is positive, as it will be in the model (12), $\sigma_{r}=0$ would of course satisfy the inequality. The empirical estimates of (16), in Table II, column (7), however, were negative; the minimum return variability needed to explain the Table II results is given by the positive $\sigma_{r}$ that makes (23) hold with equality.

This lower bound $\sigma_{r}$ was calculated for all seven of the specifications. $\sigma_{\mathrm{u}}^{2}, \sigma_{\mathrm{v}}^{2}, \delta_{1}$ and $\mathrm{b}$ were set equal to the estimated values reported in Table II. When dividends were assumed stationary, $\bar{d}$ was set equal to mean dividends, $\bar{d}=T^{-1} \sum d_{t}$. When dividends were assumed nonstationary, $\bar{d}$ was set equal to average expected discounted dividends, $\bar{d}=(1-b) t_{t=1}^{\infty} b^{t-1} E_{0} d_{t}$, where: $E_{0} d_{t}=E_{0} d_{0}+t E \Delta d_{t}, E_{0} d_{0}=d_{0}, d_{0}$ the level of dividends at the beginning of the sample, and $E \Delta d_{t}$ calculated as $T^{-1} \Sigma \Delta d_{t}$. The parameter a was in all cases set to $-\bar{d} / \bar{r}$, with $\bar{r}$ defined implicitly by $(1+\bar{r})^{-1}=\mathrm{b}$.

The resulting lower bound values may be found in Table IVB. They are rather large. None of the estimates are less than .12 . With $\sigma_{r}=.12$ and $\bar{r}=.07$, a two standard deviation confidence interval for the (real) expected return is about -17 percent to +31 percent. This would seem to be an implausibly large 
range.

In the linearized model considered here, then, variation in ex ante discount rates do not plausibly explain the excess variability of stock prices. How well this conclusion applies to any given nonlinear model of course depends on how well the linear model approximates the nonlinear one. An example in Shiller [33] suggests that if dividends are stationary the approximation can be quite good, even when changes in expected returns are larger than are typically considered reasonable. It is of course debatable that the approximation makes any sense, let alone is very accurate, if dividends are nonstationary. But the results here can in any case be said not to lend support to the hypothesis that the excess price variability reported in Table II is solely due to variation in expected returns.

\section{VI.Conclusions}

This paper has derived and applied a stock price volatility test. The test required neither of two strong assumptions required by the shiller [33] volatility test: that prices and dividends have finite variance, and that a satisfactory approximation to a perfect foresight price can be calculated from a finite data series.

The test indicated that stock prices are too volatile to be the expected present discounted value of dividends, with a constant discount rate. Possible explanations for the test results include that expectations are not rational, that discount rates vary and that there are speculative bubbles. The econometric diagnostics and the informal analysis were notably more consistent with the bubble explanation than with the other two.

A detailed case for bubbles, or, for that matter, any other factor as the explanation of the excess volatililty is, however, beyond the scope of this paper. A challenging task for future research is to make such a case, reconciling the apparently excessive price volatility with the apparently good performance of a rational expectations, constant discount rate specification. 


\section{FOOTNOTES}

1. I thank A. Blinder, J. Campbell, G. Chow, S. Fischer, R. Flood, L.P. Hansen, W. Newey, J. Rotemberg, R. Trevor, and J. Taylor for helpful comments and discussions, and the National Science Foundation for partial financial support. Responsibility for remaining errors is my own. This paper was revised while I was a National Fellow at the Hoover Institution.

2. While Blanchard and Watson [4] do suggest examining the inequality that is the focus of this paper, they do not formally establish the validity of the inequality, consider possible nonstationarity of dividends or prices, or test the inequality rigorously. Subsequent to the initial circulation of this paper, however, M. Watson sent me a proof of this inequality that is valid when prices and dividends are stationary.

3. I thank J. Campbell for this proof. I also thank L.P. Hansen and M. Watson for providing alternative proofs. S. Leroy has suggested to me that a similar proposition is implied in Leroy and Porter [21,p568]. My own, rather tedious, proof may be found in an earlier version of this paper [41].

4. Elaboration on the first three comments: (1)I believe that $x_{t I}$ and $x_{t H}$ are always well defined, given the assumptions of Proposition 1. The statement in the text specifies finite parameter ARIMA models because to my knowledge the theory for prediction of linear processes, which is well developed for stationary variables, has been extended to nonstationary variables only for such models. See Hansen and Sargent [17] for the ARIMA $(q, s, 0)$ case. It follows from Hansen and Sargent [17] that $x_{t I}$ and $x_{t H}$ exist for the ARIMA 
$(q, s, r)$ case. This is because after $r$ periods, the expectations follow the same difference equation in each case. So if the discounted sum $f$ or an arbitrary ARIMA $(q, s, 0)$ process converges, so does that for an arbitrary ARIMA $(q, s, r)$ process. (Strictly speaking, this statement does not hold for a process with a unit MA root and an infinite past, which may be the case for a stationary ARMA $(q, r)$ process, since such a process does not have a convergent autoregressive representation. See Granger and Newbold [10,pp142-145].)

(2) In this case, $x_{t H}=k d_{t}=k d_{t-1} \exp \left(\varepsilon_{t}\right)$ for a certain constant $k$ (Kleidon [20]). So $E x_{t H} \mid H_{t-1}=k d_{t-1} \operatorname{Eexp}\left(\varepsilon_{t}\right)$, and $x_{t H}-E x_{t H} \mid H_{t-1}$ is proportional to $d_{t-1}$. An interesting project for future research is to develop an analogue of equation (1) that holds when logs or $l o g$ differences are required to induce stationarity.

(3) An example: Let $n=1$, so $x_{t}=d_{t}+b d_{t+1}$. Suppose $d_{t} \sim M A(1), d_{t}=v_{t}+\theta v_{t-1},-1<\theta<1$; $H_{t}=\left\{d_{t-j} \mid j \geq 0\right\}=\left\{v_{t-j} \mid j \geq 0\right\} ; \quad I_{t}=\left\{d_{t-j}, v_{t-j+1} \mid j \geq 0\right\}=\left\{v_{t-j+1} \mid j \geq 0\right\} . \quad$ Then $x_{t H}-E x_{t H}\left|H_{t-1}=(1+b \theta) v_{t}, x_{t I}-E x_{t I}\right| I_{t-1}=b v_{t+1}$. Inequality (1) will be violated if, for example, $b=.9$ and $\theta<-.2$.

The reason the proof of (1) cannot be adapted to the finite horizon case is that a term of the form $b^{n+1} x_{t+n+1, I}$ will appear in equation (4), with an analogous term in equation (5). The fact that $x_{t I}$ exists means that $b^{n+1} x_{t+n+1, I}$ is expected to get arbitrarily small for arbitrarily large $n$, and so can be ignored in the infinite horizon case. But for any finite $n$, the term cannot be ignored, and the argument in the proof will not apply.

5. To emphasize that inequality (13) holds even when dividends and prices are nonstationary, it is perhaps worth considering the class of dividend and price processes studied by Marsh and Merton [25]. Marsh and Merton argue that both theory and empirical evidence on dividends suggest that dividends are a 
distributed lag on prices: $d_{t}=\sum \theta_{i} p_{t-i}=\theta(L) p_{t}$. They also show that if dividends in fact are such a distributed lag on prices, and if dividends and prices are nonstationary, the basic Shiller [33] volatility test is no longer valid.

The test in this paper is, however, still valid if dividends are a distributed lag on prices and dividends are nonstationary. For it may be shown that $d_{t}=\theta(L) p_{t}$ and $p_{t}=E \sum b^{i} d_{t+i} \mid I_{t}$ together imply that $H_{t}=I_{t}-$ only lagged dividends are used to forecast future dividends. When $H_{t}=I_{t}$, inequality (13) holds trivially, as a strict equality. (See footnotes 5 and 6 in West [41].) Even when dividends and prices are determined as suggested by Marsh and Merton [25], then, a violation of inequality (13) is evidence against the model (12).

6. Proposition 1 assumed that variables had zero mean. If not, $H_{t}$ and $I_{t}$ must be expanded to include suitable deterministic terms. In the annual data used here, a constant is the only relevant such term.

7. In fact, in some empirical work the variable that is here called $d_{t+1}$ is assumed known at time $t$ and thus has an innovation of zero when forecast at time t (Shiller [33], Leroy and Porter [21]).

8. Even if there are bubbles, the right hand side of (19) clearly is not gauranteed to be larger, and, in particular, will not be larger in the (implausible) case of a purely deterministic bubble, $c_{t}=b^{-t} c_{0}$. A related paper (West [39]) develops and applies a test that is capable of finding such a bubble. The results of that paper are consistent with the results of this paper. 
Since the test in west [39] is a test of cross equation restrictions, similar to the tests developed in Sargent [31] and Hansen and Sargent [17], this seems the appropriate place to comment on Hansen and Sargent's [16] point that tests of cross equation restrictions test all the restrictions of a linear rational expectations model, while volatility tests do not. The latter part of this statement is illustrated for the present paper's test by the comments in the preceding paragraph.

There are at least two reasons why stock market volatility tests are valuable nonetheless. The first is that a volatility test may have more power against a paricuiar aiternative than a test of cross equation restrictions. In the present context, this is perhaps reflected by the stronger rejection of the null in the present paper than in west [39], for differenced specifications. The second is that if a model is rejected by both tests, characterization of prices as "excessively volatile" may to some economists be a more provocative stimulus to future research than is a characterization of prices as "failing to obey cross equation constraints." That a characterization as "excessively volatile" is provocative to some is perhaps evidenced by the the strong reaction, both favorable and unfavorable, to the Shiller [33] volatility test.

In any case, the West [39] test of cross equation restrictions and the present paper are complementary studies. Those who argue for regression tests instead of volatility tests (see the discussion Hansen and Sargent [16]) are likely to prefer west [39], while those who argue for the converse (see the discussion in Shiller [34]) are likely to prefer the present paper.

9. Standard diagnostic tests will not suffice to find a misspecification of the dividend equation if the sample size is not large enough to infer the 
-F5-

parameters of the true dividend process. This might be the case because a small probability event, which is rationally considered by market participants, has not occurred. The best protection against such a biased sample is obviously to use a large sample, which is what I did.

In addition, it is worth noting that one important example of such a low probability event is allowed in the present framework. Suppose the market is considering a disaster such as nationalization that will set dividends to zero. The probability of disaster is $\theta$. Shiller [34] shows that equation (9) is still valid, with $b$ interpreted as the product of a discount rate and $1-\theta$. It follows that if (12) is true, (13) should hold.

10. For a nice general equilibrium model that allows bubbles, see Tirole [37]; it is perhaps worth noting that in Tirole's deterministic, perfect foresight steady state, asset returns are constant, just as are expected returns in the stochastic environment considered here. For an argument that volatility tests cannot be used to infer the presence of bubbles, see Hamilton and Whiteman [12].

11. The Hannan-Quinn procedure selects the $r$ that minimizes

$$
\ln \sigma_{\mathrm{v}}^{2}+\mathrm{T}^{-1} 2 \mathrm{rk} \ln \ln \mathrm{T}, \sigma_{\mathrm{v}}^{2}=\mathrm{T}^{-1} \sum \mathrm{v}_{\mathrm{t}}^{2}
$$

for $r<R$ for some fixed $R$, with $k>1$. I set $R=4, k=1.001$.

12. Suppose discount rates are time varying. Let $b_{t}$ be the one period rate from perlod $t$ to period $t+1, \bar{b}$ the probability limit of the instrumental variables estimate of the discount rate in equation (14), and $n_{t+1}=p_{t+1}+d_{t+1}$. The proper specification of equation (1) is thus $p_{t}=b_{t} E n_{t+1} \mid I_{t}$. Equation (14) is then 


$$
p_{t}=\bar{b} n_{t+1}+\left(b_{t}-\bar{b}\right) n_{t+1}+b_{t}\left(n_{t+1}-E n_{t+1} \mid I_{t}\right)=\bar{b} n_{t+1}+u_{t+1} \text {. }
$$

In general the instruments (lagged dividends) will be correlated with the residual $u_{t+1}$ since they will be correlated with $\left(b_{t}-\bar{b}\right) n_{t+1}=$ $\left(b_{t}-\bar{b}\right)\left(p_{t+1}+d_{t+1}\right)$. The only apparent exceptions are implausible or uninteresting -- e.g., when $b_{t}-\bar{b}$, the deviation of ex-ante rates from a fixed level, is uncorrelated with both $p_{t+1}+d_{t+1}$ and with lagged dividends ( $t$ he instruments).

Observe also that in general the residual to the equation above will be serially correlated when discount rates are not constant (i.e=s when $b_{t}$ not equal $\bar{b}_{t}$ for all $t$ ). Thus testing for serial correlation in the residual to (14) checks not only whether expectations are rational but also whether discount rates are constant.

13. This seems an appropriate place to give the results of another test of this model. Equation (6) states that $\operatorname{var}\left(x_{t}-x_{t H}\right)-\operatorname{var}\left(x_{t}-x_{t I}\right)-\operatorname{var}\left(x_{t I}-x_{t H}\right)=0$. So, under the null hypothesis that $x_{t I}=p_{t}+d_{t}$,

$$
\delta_{1}^{2} \sigma_{v}^{2}-b^{-2} \sigma_{u}^{2}-b^{-2}\left(1-b^{2}\right) \operatorname{var}\left[p_{t}+d_{t}-\left(m+\sum_{i}^{q+s} \delta_{i} d_{t-i+1}\right)\right]=0
$$

The parameters needed to calculate $x_{t H}$ under the null--m, $\delta_{1}, \ldots, \delta_{q+s}--$ are complicated functions of $b, \mu$, and the $\phi_{i}$. The formula for $m$ may be found in West [39], for the $\delta_{i}$ in Hansen and Sargent [17].

I tested this equality constraint for all seven specifications, with the number of lags used in the calculation of the matrix $\hat{S}$ (defined in the appendix) set to 11 . The z-statistics for the seven specifications, presented in the same order as in Table II, were: $1.88,2.07,1.71,2.23,1.85,2.17$, 1.71. Thus this suggests some mild evidence against the null hypothesis. The basic reason for the relatively low statistics was a very noisy estimate of $\operatorname{var}\left[p_{t}+d_{t}-\left(m+\sum_{1}^{q+s_{\delta}} d_{t-i+1}\right)\right]$. This was insignificantly different 
from zero at the five per cent level, for all seven specifications. One possible reason for this noisy estimate is that there are bubbles: if so, $\operatorname{var}\left[p_{t}+d_{t}-\left(m+\sum_{1}^{q+s} \delta_{i} d_{t-i+1}\right)\right]$ is not even finite.

14. I thank R. Flood for pointing this out to me.

15. Note that the entries in the table are not a monotonic function of $\alpha$. To make sure that the entries were representative, I calculated the percentage excess variability for $\alpha$ in steps of 0.1 from 0 to 3.0 , in steps of 1.0 from 3.0 to 10.0 , and in steps of 5.0 from 10.0 to 50.0 . The results were quite similar to those reported in the table. The lowest percentage happened to occur at $\alpha=2.0$.

16. In the linearized model the analogue to equation equation (9) is $p_{t}=b E\left[a\left(r_{t}-\bar{r}\right)+d_{t+1}+p_{t+1}\right] \mid I_{t}$. Let $y_{t+j}=a\left(r_{t+j-1}-\bar{r}\right)+d_{t+j}$ and redef ine $x_{t}=\sum b^{j} y_{t+j}, x_{t I}=E x_{t} \mid I_{t}$. (Of course, if expected returns are constant, $r_{t}=\bar{r}$ for all $t, x_{t}$ and $x_{t I}$ as defined here reduce to their Proposition 1 counterparts.) The efficient markets model considered in section III implied $x_{t I}=d_{t}+p_{t}$; the one currently under consideration implies $x_{t I}=y_{t}+p_{t}=a\left(r_{t-1}-\bar{r}\right)+d_{t}+p_{t}$. So with $r_{t-1}$ an element of $I_{t-1}, x_{t I}-E x_{t I} \mid I_{t-1}=d_{t}+p_{t}-E\left(d_{t}+p_{t} \mid I_{t-1}\right)$. Now,

$$
\text { (*) } \begin{aligned}
u_{t+1}=p_{t}-b\left(d_{t+1}+p_{t+1}\right)=\left[b a\left(r_{t}-\bar{r}\right)+b E\left(p_{t+1}+d_{t+1} \mid I_{t}\right)-b\left(d_{t+1}+p_{t+1}\right)\right] \\
=b\left[a\left(r_{t}-\bar{r}\right)-\left(x_{t+1, I}-E x_{t+1, I} \mid I_{t}\right)\right] \\
\Rightarrow b^{-2} \sigma_{u}^{2}=a^{2} \sigma_{r}^{2}+E\left(x_{t+1, I}-E x_{t+1, I} \mid I_{t}\right)^{2} \\
\Rightarrow E\left(x_{t+1, I}-E x_{t+1, I} \mid I_{t}\right)^{2}=b^{-2} \sigma_{u}^{2}-a^{2} \sigma_{r}^{2}
\end{aligned}
$$

Now define $J_{t}$ as the space spanned by a constant and all current and lagged 
dividends and expected returns, $x_{t J}=E x_{t} \mid J_{t}$. Let $x_{t J}-E x_{t J} \mid J_{t-1}=a w_{1 t}+w_{2 t}$, where $w_{1 t}$ and $w_{2 t}$ are the innovations in the expected present discounted values of $r_{t}$ and $d_{t}$. Shiller [35] shows that $\sigma_{w_{1}}^{2} \leq \sigma_{r}^{2} /\left(1-b^{2}\right)$. Assume that $d_{t}$ or $\Delta d_{t}$ follows the autoregression (15). Then since $H_{t}$ is a subset of $J_{t}$, Proposition 1 tells us that $\sigma_{\mathrm{w}_{2}}^{2} \leq \delta_{1}^{2} \sigma_{\mathrm{v}}^{2}$, where, as previously, $\sigma_{\mathrm{v}}^{2}$ is the variance of the univariate dividend innovation and $\delta_{1}$ is defined above equation (16). So

$(* *)$

$$
\begin{aligned}
E\left(x_{t J}-E x_{t J} \mid J_{t-1}\right)^{2} & =a^{2} \sigma_{w_{1}}^{2}+2 a \sigma_{w_{1} w_{2}}+\sigma_{w_{2}}^{2} \\
& \leq a^{2} \sigma_{w_{1}}^{2}+2 a \sigma_{w_{1}} \sigma_{w_{2}}+\sigma_{w_{2}}^{2} \\
& \leq\left(1-b^{2}\right)^{-1} a^{2} \sigma_{r}^{2}+2 a\left(1-b^{2}\right)^{-1 / 2} \delta_{1} \sigma_{v} \sigma_{r}+\delta_{1} \sigma_{v}^{2}
\end{aligned}
$$

Since $J_{t}$ is a subset of $I_{t}$, Proposition 1 tells us that $E\left(x_{t I}-E x_{t I} \mid I_{t-1}\right)^{2} \leq$ $E\left(x_{t J}-E x_{t J} \mid J_{t-1}\right)^{2}$. So with a little rearrangement, $(*)$ and $\left(*^{*}\right)$ together imply equation (23) in the text. 


\section{APPENDIX}

This describes the calculation of the variance-covariance matrix of the parameter vector $\theta=\left(b, \phi, \sigma_{u}^{2}, \sigma_{v}^{2}\right)=\left(b, \mu, \phi_{1}, \ldots, \phi_{q}, \sigma_{u}^{2}, \sigma_{v}^{2}\right)$. It also establishes suitable conditions for the calculation to be appropriate when dividends are assumed nonstationary .

Let $z_{t}=\left(1, \Delta^{s} d_{t}, \ldots, \Delta^{s} d_{t-q+1}\right)$, be the $(q+1) \times 1$ vector of instruments, $s=0$ or $s=1, n_{t+1}=\left(d_{t+1}+p_{t+1}\right)$ be the right hand side variable in (14). One way of describing the estimation technique is to note that $\hat{\theta}$ was chosen to satisfy the orthogonality condition

$$
0=T^{-1} \sum n_{t}(\hat{\theta})=\left[\begin{array}{l}
T^{-1}\left(\Sigma n_{t+1} Z_{t}^{\prime}\right)\left(T \hat{S}_{z}\right)^{-1} \Sigma Z_{t}\left(p_{t}-n_{t+1} \hat{b}\right) \\
T^{-1} \sum Z_{t}\left(d_{t+1}-Z_{t}^{\prime} \hat{\phi}\right) \\
\hat{o}_{u}^{2}-T^{-1} \Sigma\left(p_{t}-n_{t+1} \hat{b}\right)^{2} \\
\hat{\sigma}_{v}^{2}-T^{-1} \Sigma\left(d_{t+1}-z_{t}^{\prime} \hat{\phi}\right)^{2}
\end{array}\right]
$$

(The degrees of freedom corrections in $\hat{\sigma}_{u}^{2}$ and $\hat{\sigma}_{v}^{2}$ are suppressed for notational simplicity.) The sumations in the orthogonality condition run over t, from 1 to $T . \hat{S}_{z}$ is an estimate of $E Z_{t} z_{t} u_{t+1}^{2}$, calculated as described below equation (21). Thus $\hat{b}$ is estimated by two step, 2SLS, $\hat{\phi}$ by oLS, $\hat{\sigma}_{u}^{2}$ and $\hat{\sigma}_{v}^{2}$ from moments of the residuals.

Since $\operatorname{En}_{t}(\theta)=0$, where $\theta$ is the true but unknown parameter vector, it may be shown that under fairly general conditions, $\sqrt{ } T(\hat{\theta}-\theta)$ is asymptotically normal with a covariance matrix $V=\left(p l i m T^{-1} \sum h_{t \theta}\right)^{-1} S\left(p l i m T^{-1} \sum h_{t \theta}\right)^{-1}$ (Hansen [15], White and Domowitz [42]). $h_{t \theta}$ is the $(q+4) x(q+4)$ matrix of derivatives of $h_{t}$ with respect to $\theta$ and $s=E h_{t} h_{t}^{\prime}+j_{j=1}^{\infty}\left[E h_{t} n_{t-j}^{\prime}+\left(E h_{t} h_{t-j}^{\prime}\right)^{\prime}\right]$. $h_{t \theta}$ is straightforward to calculate. Calculation of $S$ is slightly more involved. Newey and West [27] show that in general $S$ and thus $V$ are consistently 
estimated if $\hat{S}=\hat{\Omega}_{0}+\sum_{i=1}^{m} w(i, m)\left(\hat{\Omega}_{i}+\hat{\Omega}_{j}\right)$, where: $m-\rightarrow \infty$ as $T \rightarrow-\infty$ and $m$ is $o\left(T^{1 / 4}\right) ; \quad w(i, m)=i /(m+1) ; \hat{a}_{1}=T^{-1} \sum_{t=i+1}^{T} \tilde{h}_{t} \tilde{h}_{t-i}, \tilde{h}_{t}=h_{t}(\tilde{\theta}), \bar{\theta}$ an 1nit1al consistent estimate (2SLS and OLS). The weights $w(1, m)$ insure that $\hat{S}$ is positive definite. In the absence of any theoretical or Monte Carlo evidence on the small sample properties of various choices of $m$, I tried various values: $m=3.7$ or 11 . The value of $m$ that led to the largest standard error in column (7) of Table II is what is reported in Table II. For all specifications, this turned out to be $m=11$.

The conditions in Hansen [15], White and Domowitz [42] and Newey and West [27] unfortunately do not cover the case when $n_{t+1}$ is nonstationary. The formulas just given are, however, still basically applicable, at least under the conditions listed in the assumptions given below. The only difference between the stationary and the nonstationary cases is that a certain term in $h_{t \theta}$ that depends on $\mathrm{plimT}^{-1} \Sigma n_{t+1} u_{t+1}$ is set to zero in the nonstationary case.

The remainder of this appendix sketches the argument necessary to establish the asymptotic distribution of $\hat{\theta}$ in the nonstationary case. A detailed argument is available on request.

Theorem 1 below establishes the asymptotic distribution of $\hat{b}$. Theorem 2 . that of $\sigma_{u}^{2}$. Theorem 3 that of the Joint asymptotic distribution of the elements of $\hat{\theta}$. (In light of assumption (a4) below, standard theory applies for $\hat{\phi}$ and $\hat{o}_{v}^{2}$ )

Assumptions.

(a1) Let $w_{t}$ be the $(2 q+4) \times 1$ vector $\left(z_{t} u_{t+1}, z_{t} v_{t+1}, u_{t+1}^{2}-\sigma_{u}^{2}, v_{t+1}^{2}-\sigma_{v}^{2}\right)$. . Then $w_{t}$ is (i)ergodic and covariance and fourth order stationary, with (11)iid innovations, and (1ii)a moving average representation whose weights are absolutely sumable.

(a2) The innovations in the $\left(y_{t}, z_{t}\right)$ process are zero for all $t \leq t_{0}$, for some 
$t_{0}$ s-q; $n_{t_{0}+1}$ is a nonstochastic constant, that, for simplicity is assumed to be zero.

$\underline{(a 3)} E \Delta n_{t} \neq 0$

(a4) The $\left(\Delta n_{t}, \Delta d_{t}\right)$ process is covariance stationary, with a moving average representation whose weights are absolutely summable.

Remark. The heart of the argument is in the lemma, which proves that $T^{-2} \sum Z_{t} n_{t+1}$ converges in probability to a matrix of constants of rank one. Asymptotic normality then follows easily. The convergence in probability is established by showing that $11 m\left(E_{t_{0}} T^{-2} \Sigma Z_{t}{ }^{n} t+1\right)$ is a vector of constants of rank one and $\lim \left[\operatorname{var}_{t_{0}}\left(T^{-2} \sum z_{t} n_{t+1}\right)\right]$ is zero. $\left(E_{t_{0}}\right.$ and $\operatorname{var}_{t_{0}}$ denote expectations and variances calculated conditional on the history of the $\left(y_{t}, z_{t}\right)$ process at date $t_{0}$; by assumption (a2), this means expectations and variances calculated assuming that all past innovations in the $\left(y_{t}, z_{t}\right)$ process are zero.) In reading the lemma, It will be helpful to note that (a)by $(a 2), E_{t_{0}} \mathbf{y}_{t}=E_{t}$ and $E_{t_{0}} z_{t}=E z_{t}$, for all $t \geq t_{0} ;(b) \operatorname{var}_{t_{0}}(.) \leq \operatorname{var}($.$) , where (.) is any function of$ $y_{t}^{\prime} s$ and $z_{t}^{\prime} s, t z t_{0}$, with rinite unconditional variance. The unconditional operators $E($.$) and \operatorname{var}($.$) are understood to act as if the y_{t}$ and $z_{t}$ processes have infinite pasts, 1.e., these operators do not condition on assumption (a2).

Lemma. $T^{-2} \sum Z_{t} n_{t+1}$ converges in probability to a $(q+1) \times 1$ constant vector of rank 1.

Proof: The first element of $T^{-2} \Sigma Z_{t} n_{t+1}$ is $T^{-2} \sum n_{t+1}$. I will show that this converges in probability to (1/2)E $\Delta n_{t}$, which is nonzero by (a3). A similar but considerably messier argument can be used to establish that each of the other elements or $T^{-2} \Sigma Z_{t} n_{t+1}$ converge in probability to a constant.

We have $\Sigma n_{t+1}=I n_{1}+\Sigma\left(n_{t+1}-n_{1}\right)$. It is easliy shown that (a2) implies that $\lim \left[E_{t_{0}} T^{-2}\left(T n_{1}\right)\right]=11 m\left[\operatorname{var}_{t_{0}} T^{-2}\left(T n_{1}\right)\right]=0$. Now, $n_{t+1}=\Delta n_{t+1}+\ldots+\Delta n_{2}+$ 
$n_{1}$. It follows that

$$
\text { (A.1) } \quad \begin{gathered}
\quad\left[\left(n_{t+1}-n_{1}\right)=\Delta n_{2}+\left(\Delta n_{2}+\Delta n_{3}\right)+\ldots+\left(\Delta n_{2}+\ldots+\Delta n_{T+1}\right)\right. \\
=T \Delta n_{2}+(T-1) \Delta n_{3}+\ldots+\Delta n_{T+1} \\
\Rightarrow \quad E\left[\left(n_{t+1}-n_{1}\right)=[T+(T-1)+\ldots+1] E \Delta n_{t}\right. \\
=\left[\left(T^{2}+T\right) / 2\right] E \Delta n_{t} \\
\Rightarrow \quad 11 m T^{-2} E\left[\left(n_{t+1}-n_{1}\right)=(1 / 2) E \Delta n_{t}\right.
\end{gathered}
$$

Let $r(j)$ denote $\operatorname{cov}\left(\Delta n_{t}, \Delta n_{t-j}\right)$. As stated in the Remark, to establish that Iim $\operatorname{var}_{t_{0}}\left[T^{-2} \sum\left(n_{t+1}-n_{1}\right]\right)=0$, it suffices to establish that lim $\operatorname{var}\left[T^{-2} \Sigma\left(n_{t+1}-n_{1}\right]\right)=0$. To show this, note that (A.1) implies

$$
\begin{aligned}
\operatorname{var}\left[\Sigma\left(n_{t+1}-n_{1}\right)\right] & =\left[T^{2}+(T-1)^{2}+\ldots 1^{2}\right] \gamma(0) \\
& +2[T(T-1)+(T-1)(T-2)+\ldots+2.1] \gamma(1) \\
& +\ldots+2[T \cdot 1] \gamma(T-1) \\
& \leq\left(\Sigma t^{2}\right)\left[\gamma(0)+2{ }_{j}^{T} \bar{\Sigma}_{j}^{1}|\gamma(j)|\right] \\
& \leq\left(\Sigma t^{2}\right)\left[\gamma(0)+22_{j=1}^{\infty}|\gamma(j)|\right]
\end{aligned}
$$

Assumption (a4) implies that the right hand side of the above is finite for given $T$ (Hannan $[13, p 211]$ ). The fact that $\sum t^{2}$ is of order $T^{3}$ now implies that 1 im $\operatorname{var}\left[T^{-2} \sum\left(n_{t+1}-n_{1}\right)\right]$ is zero. So $T^{-2} \Sigma n_{t+1}$ converges in mean square and thus in probability to $(1 / 2) E \Delta n_{t}$.

Theorem 1. $T^{3 / 2}(\hat{b}-b)$ converges in distribution to a $N\left(0, v_{b}\right)$ random variable, $v_{b}=\operatorname{plim}\left[\left(T^{-2}\left[n_{t+1} Z_{t}\right) S_{z}^{-1}\left(T^{-2}\left[Z_{t} n_{t+1}\right)\right]^{-1}\right.\right.$.

Proof: We have

$$
\begin{aligned}
& T^{3 / 2}(\hat{b}-b)= \\
& \quad\left[\left(T^{-2} \Sigma n_{t+1} z_{t} \cdot\right) \hat{S}_{z}^{-1}\left(T^{-2} \Sigma Z_{t} n_{t+1}\right)\right]^{-1}\left(T^{-2} \Sigma n_{t+1} Z_{t}{ }^{\prime}\right) \hat{S}_{z}^{-1}\left(T^{-1 / 2} \Sigma Z_{t} u_{t+1}\right)
\end{aligned}
$$


Assumption (a1) insures that $(a) T^{-1 / 2} \Sigma Z_{t} u_{t+1}$ converges in distribution to a $N\left(0, S_{z}\right)$ random variable, and (b)plim $\hat{S}_{z}=S_{z}$. The lemma insures that $T^{-2} \Sigma Z_{t} n_{t+1}$ converges in probability to a constant vector of rank 1 . The theorem now follows.

Theorem 2. $\sqrt{T}\left(\mathrm{~T}^{-1} \sum \hat{u}_{t}^{2}-\sigma_{u}^{2}\right)$ has the same asymptotic distribution as $\sqrt{T}\left(T^{-1} \Sigma u_{t}^{2}-\sigma_{u}^{2}\right)$. (Note: summation signs here and in the proof of Theorem 2 run from 2 to $T+1$.)

Proof: We have

$$
\begin{aligned}
& \hat{u}_{t}^{2}=\left(p_{t-1}-n_{t} \hat{b}\right)^{2}=u_{t}^{2}-2(\hat{b}-b) n_{t} u_{t}+(\hat{b}-b)^{2} n_{t}^{2} \\
& \Rightarrow \quad J T\left(T^{-1} \Sigma u_{t}^{2}-\sigma_{u}^{2}\right)=V T\left(T^{-1} \Sigma u_{t}^{2}-\sigma_{u}^{2}\right) \\
& -2\left[T^{3 / 2}(\dot{b}-b)\right]\left(T^{-2} \sum n_{t} u_{t}\right) \\
& +\left[T^{3 / 2}(\hat{b}-b)\right]^{2}\left(T^{-7 / 2} \sum n_{t}^{2}\right)
\end{aligned}
$$

It may be shown that $T^{-2} \sum n_{t} u_{t}$ and $T^{-7 / 2} \Sigma n_{t}^{2}$ each converge in probability to zero. For $T^{-2} \sum n_{t} u_{t}$ this follows because $E \Sigma n_{t} u_{t}$ is of order $T, \operatorname{var}\left(\sum n_{t} u_{t}\right)$ of order $T^{3}$. A similar argument applies to $T^{-7 / 2}\left[n_{t}^{2}\right.$.

Since $\mathrm{T}^{3 / 2}(\hat{\mathrm{b}}-\mathrm{b})$ has a well defined asymptotic distribtution, this implies

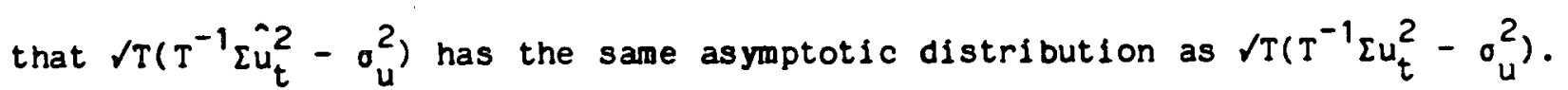
It also obviously will imply that $\hat{\sigma}_{u}^{2}$ is a consistent estimate of $\sigma_{u}^{2}$.

Theorem 3.

(a) The normalized parameter vector $\left[T^{3 / 2}(\hat{b}-b), \sqrt{T}(\hat{\phi}-\phi), V T\left(\hat{\sigma}_{u}^{2}-\sigma_{u}^{2}\right), \sqrt{ } T\left(\hat{\sigma}_{v}^{2}-\sigma_{v}^{2}\right)\right]$ converges in distribution to a $\mathrm{N}(\mathrm{O}, \mathrm{V})$ random variable, where: $\mathrm{V}=\mathrm{HS}_{W^{\prime}} \mathrm{H}^{\prime} ; \mathrm{S}_{W}=$ $E W_{t} W_{t}^{\prime}+\sum_{j=1}^{\infty}\left[E W_{t} W_{t-j}^{\prime}+\left(E W_{t} W_{t-j}^{\prime}\right)^{\prime}\right]$, $W_{t}$ defined in (a1); H is a block diagonal matrix with plim $\left[\left(T^{-2} \Sigma n_{t+1} Z_{t}\right) \hat{S}_{z}^{-1}\left(T^{-2} \Sigma Z_{t} n_{t+1}\right)\right]^{-1}\left(T^{-2} \Sigma n_{t+1} Z_{t}\right) \hat{S}_{z}^{-1}$

in the upper left hand block, plim $\left(T^{-1} \Sigma Z_{t} Z_{t}^{\prime}\right)$ in the middle block, and $a(2 \times 2)$ identity matrix in the lower right hand block. 


$$
-A 6-
$$

(b)If $\hat{S}_{w}$, the Newey and west estimate of $S_{w}$, is calculated using 2SLS and OLS residuals, $\hat{S}_{w}$ converges in probability to $S_{w}$.

Proof: It may be shown than assumption (a1) is strong enough to insure that cross products of instruments and disturbances, and of instruments and residuals calculated using estimated parameters, are well behaved. So parts (a) and (b) of the theorem both follow from Theorems 1 and 2, given assumption (a).

Note that the covariance matrix in the nonstationary case, HS $\mathrm{H}^{\prime}$, is the same as the covariance matrix in the stationary case, $\left(p \perp i m T^{-1} \sum n_{t \theta}\right)^{-1} S\left(p I I m T^{-1} \sum n_{t \theta}^{\prime}\right)^{-1}$, except that a term depending in part on plim $T^{-1} \Sigma n_{t+1} u_{t+1}$ appears in the latter but not in the former. 


\section{REFERENCES}

[1] Ackley, G.: "Commodities and Capital: Prices and Quantities," American Economic Review, 73 (1983), pp. 1-16.

[2] Anderson, T.W.: "On The Asymptotic Distributions of Parameters of Stochastic Difference Equations," Annals of Mathematical Statistics, (1959), 30, pp. 676-687.

[3] Blanchard, 0.: "The Production and Inventory Behavior of the American Automobile Industry," Journal of Political Economy, 91 (1983), pp. 364-400.

[4] Blanchard, O. and M. Watson: "Bubbles, Rational Expectations and Financial Markets," NBER Working Paper No. 945, (1982).

[5] Brealey, R. and S. Myers: Principles of Corporate Finance, New York: McGraw Hill, 1981.

[6] Deaton, A.: "Life Cycle Models of Consumption: Is the Evidence Consistent with the Theory?", manuscript, Princeton University, 1985.

[7] Diba, B. and H. Grossman: "Rational Asset Price Bubbles," National Bureau of Economic Research Working Paper No. 1059, 1983.

[8] Flavin, M.: "Excess Volatility in the Financial Markets: A Reassessment of the Empirical Evidence," Journal of Political Economy, 91 (1983), Pp. 929-956.

[9] Fuller, W.A.: Introduction to Statistical Time Series, New York: John Wiley and Sons, 1976.

[10] Granger, C.W.J. and P. Newbold: Forecasting Economic Time Series, New York: Academic Press, $19 \overline{77 .}$

[11] Grossman, S. and R. Shiller: "The Determinants of The Variability of Stock Prices," American Economic Review, 71 (1981), pp. 222-227.

[12] Hamilton, J. and C. Whiteman: "The Observable Implications of Self Fulfilling Prophecies," manuscript, University of Virginia, 1984 .

[13] Hannan, E.J.: Multiple Time Series, New York: John Wiley and Sons, 1970 .

[14] Hannan, E.J. and B.G. Quinn: "The Determination of the Order of an Autoregression," Journal of the Royal Statistical Society Series B, 41 (1979), Pp. 190-195. 
[15] Hansen, L. P.: "Large Sample Properties of Generalized Method of Moments Estimators," Econometrica, 50 (1982), pp. 1029-1054.

[16] Hansen, L. P. and T. J. Sargent: "Exact Linear Rational Expectations Models: Specification and Estimation," Federal Reserve Bank of Minneapolis Staff Report No. 71 (1981).

[17] "Formulating and Estimating Dynamics Linear Rational Expectations Models," Journal of Economic Dynamics and Control, 2 (1980).

[18] Hansen, L. P. and K. Singleton: "Generalized Instrumental Variable Estimation of Nonlinear Rational Expectations Models," Econometrica, 50 (1982), pp. 1269-1286.

[19] Keynes, J. M.: The General Theory of Employment, Interest and Money, New York: Harcourt, Brace and World, 1964.

[20] Kleidon, A. W.: "Bias in Small Sample Tests of Stock Price Rationality," Stanford University Graduate School of Business Research Paper 819R (1985).

[21] Leroy, S. and R. Porter: "The Present Value Relation: Tests Based on Implied Variance Bounds," Econometrica, 49 (1981), pp. 555-574.

[22] Leroy, S.: "Efficiency and the Variability of Asset Prices," American Economic Review, 74 (1984), pp. 183-187.

[23] Lucas, R.E. Jr.: "Asset Prices in an Exchange Economy," Econometrica 46 (1978), pp. 1429-1445.

[24] Marsh, T. A. and R. C. Merton: "Aggregate Dividend Behavior and its Implications for Tests of Stock Market Rationality," Sloan School of Management Working Paper, No. 1475-83, 1983.

[25] "Dividend Variability and Variance Bounds Tests for the Rationality of Stock Market Prices," Sloan School of Management Working Paper No. 1584-84, 1984.

[26] McCallum, B.: "Rational Expectations and the Natural Rate Hypothesis: Some Consistent Estimates," Econometrica, 44 (1976), pp. 43-52.

[27] Newey, W.K. and K.D. West: "A Simple, Positive Definite, Heteroskedasticity and Autocorrelation Consistent Covariance Matrix," Princeton University Woodrow Wilson School Discussion Paper No. 92, 1985.

[28] Pagan, A.R. and A.D. Hall: "Diagnostic Tests as Residual Analysis," Econometric Review, 2 (1983), pp . 159-218. 
[29] Rao, C.R.: Linear Statistical Inference and its Applications, New York: John Wiley and Sons, 1973.

[30] Rotemberg, J.: "Sticky Prices in the United States," Journal of Political Economy, 90 (1982), pp. 1187-1211.

[31] Sargent, T. J.: "Estimation of Dynamic Labor Demand Schedules Under Rational Expectations," pp. 463-500 in Lucas, Robert E. and Thomas J. Sargent (eds.) Rational Expectations and Econometric Practice, Minneapolis: University of Minnesota Press, 1981.

[32] Shiller, R. J.: "Rational Expectations and the Dynamic Structure of Macro Models," Journal of Monetary Economics, 4 (1981) pp. 1-44.

[33]

"Do Stock Prices Move Too Much to be Justifled by Subsequent Changes in Dividends?," American Economic Review, 71 (1981), pp. 421-436.

[34] "The Use of Volatility Measures in Assessing Market Efficiency," Journal of Finance, XXXVI (1981), pp. 291-301. "Stock Prices and Social Dynamics," Brookings Papers on Economic Activity, (2) 1984, pp. 457-498.

[36] Taylor, J. B.: "On the Conditions for Uniqueness in the Solution of Rational Expectations Models," Econometrica, 45 (1977), PP. 1377-1385.

[37] Tirole, J.: "Asset Bubbles and Overlapping Generations," Econometrica 53 (1985), pp. 1071-1100.

[38] West, K. D.: "A Variance Bounds Test of the Linear Quadratic Inventory Model," forthcoming, Journal of Political Economy, 1986.

[39]

"A Specification Test for Speculative Bubbles," manuscript, Princeton University Woodrow Wilson School Discussion paper No. 97, 1985.

[40]

"A Standard Monetary Model and The Variability of the Deutschemark - Dollar Exchange Rate, manuscript, Princeton University, 1985.

[41] "Speculative Bubbles and Stock Price Volatility," Princeton University Financial Research memorandum, No. 54 , 1985.

[42] White, H. and I. Domowitz: "Nonlinear Regression with Dependent Observations," Econometrica, 52 (1984), pp. 143-162. 


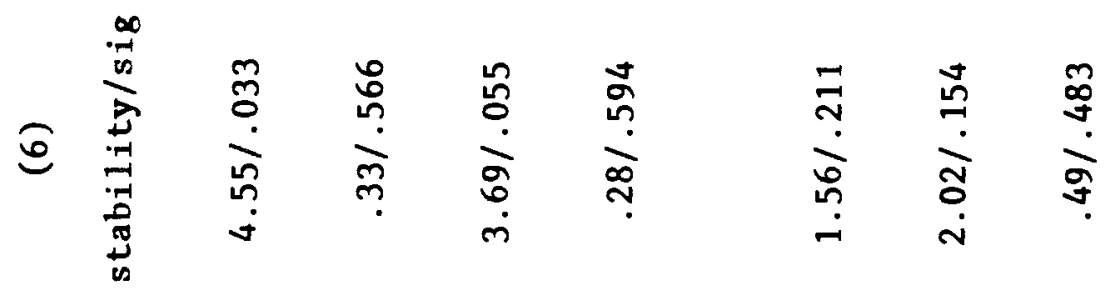

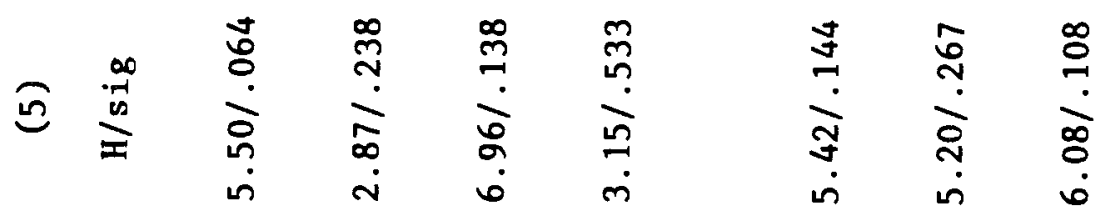

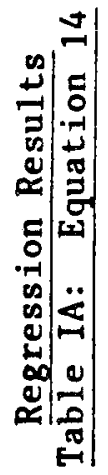

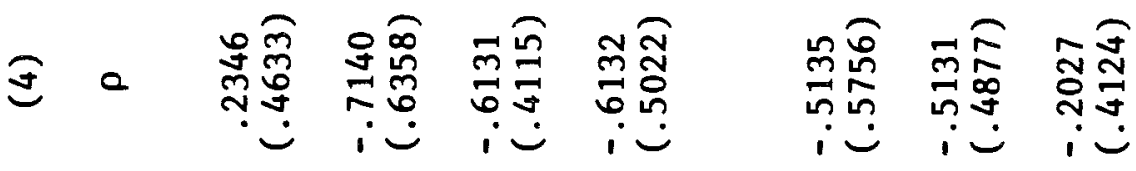

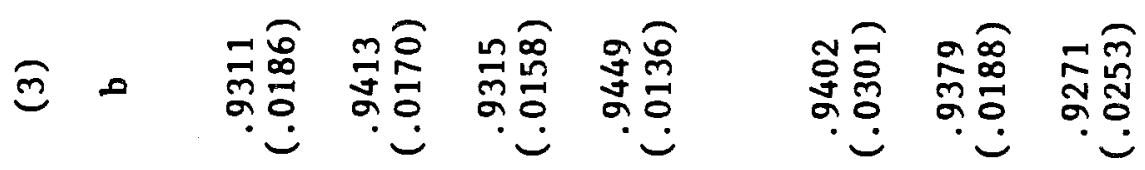

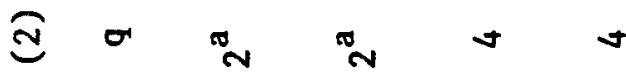

m $\quad$ o

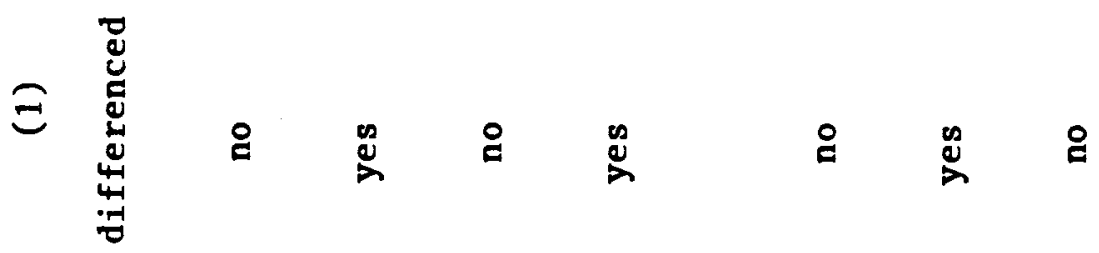

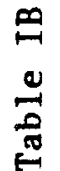

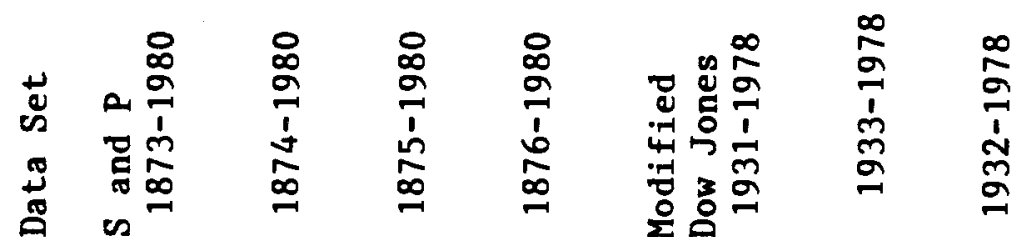

$+$

$\stackrel{8}{\stackrel{4}{\circ}}$

घั 


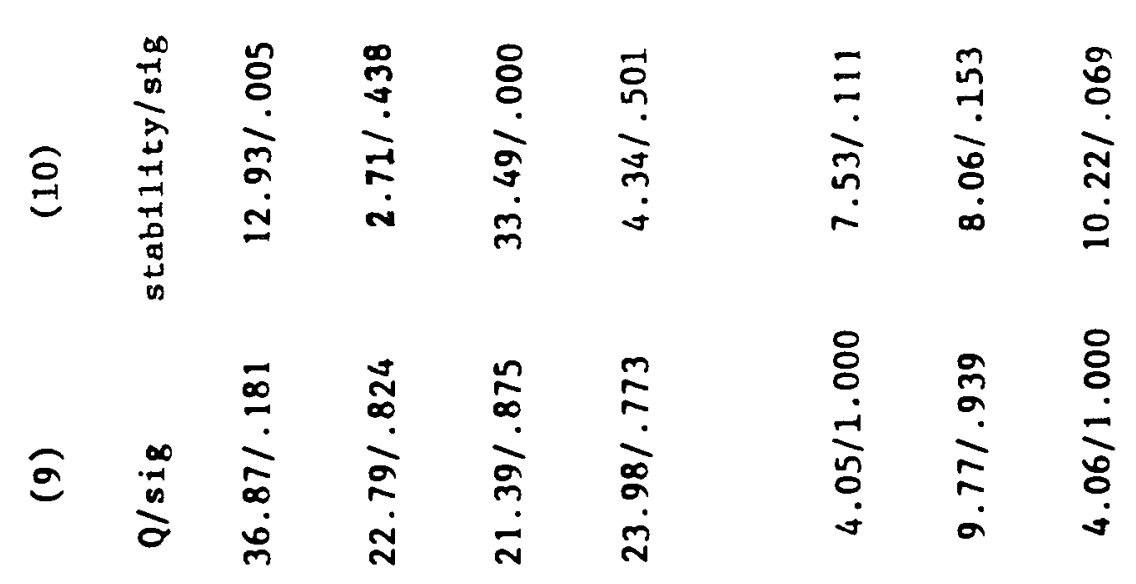

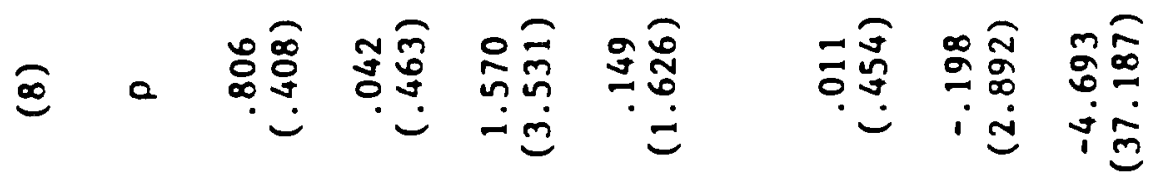

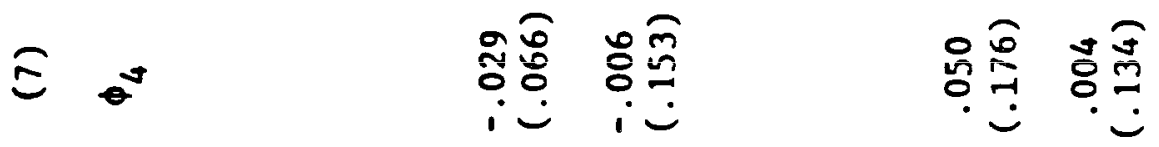

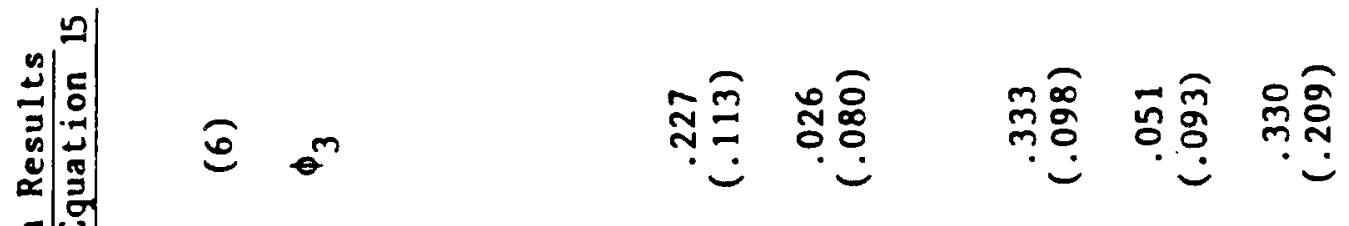

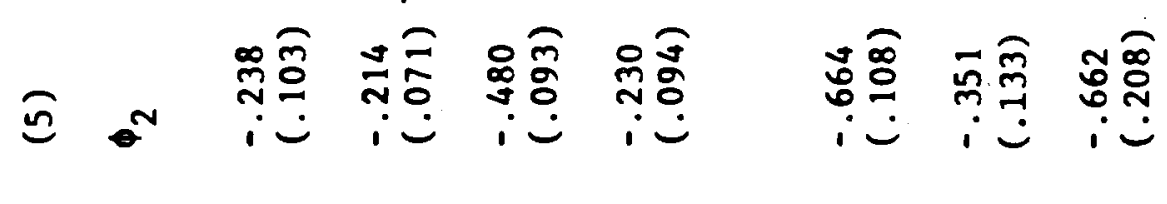

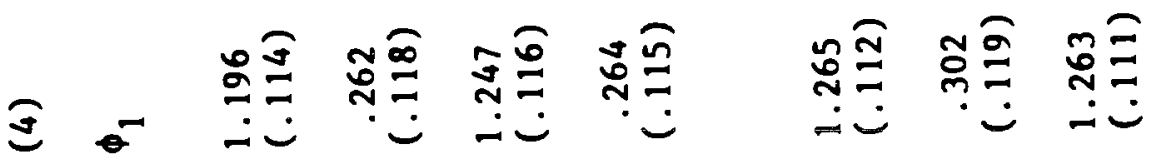

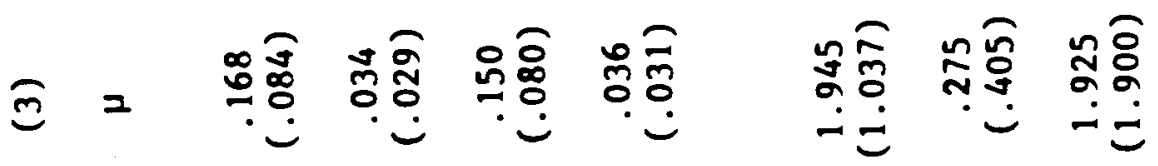

छ。 \& \& . ० क :

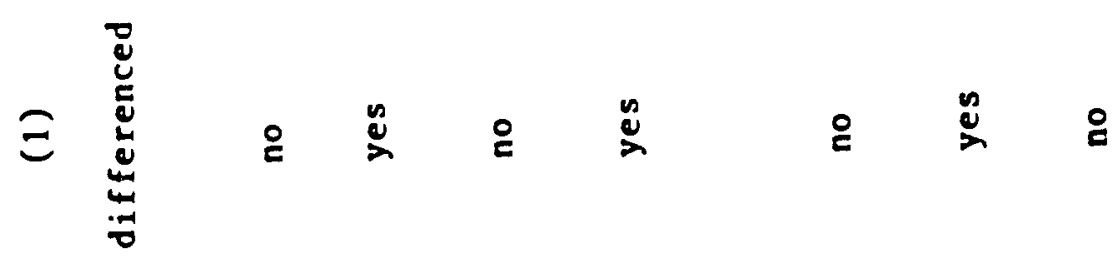

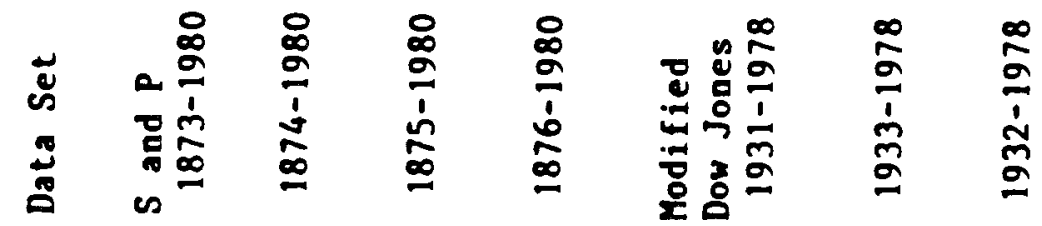




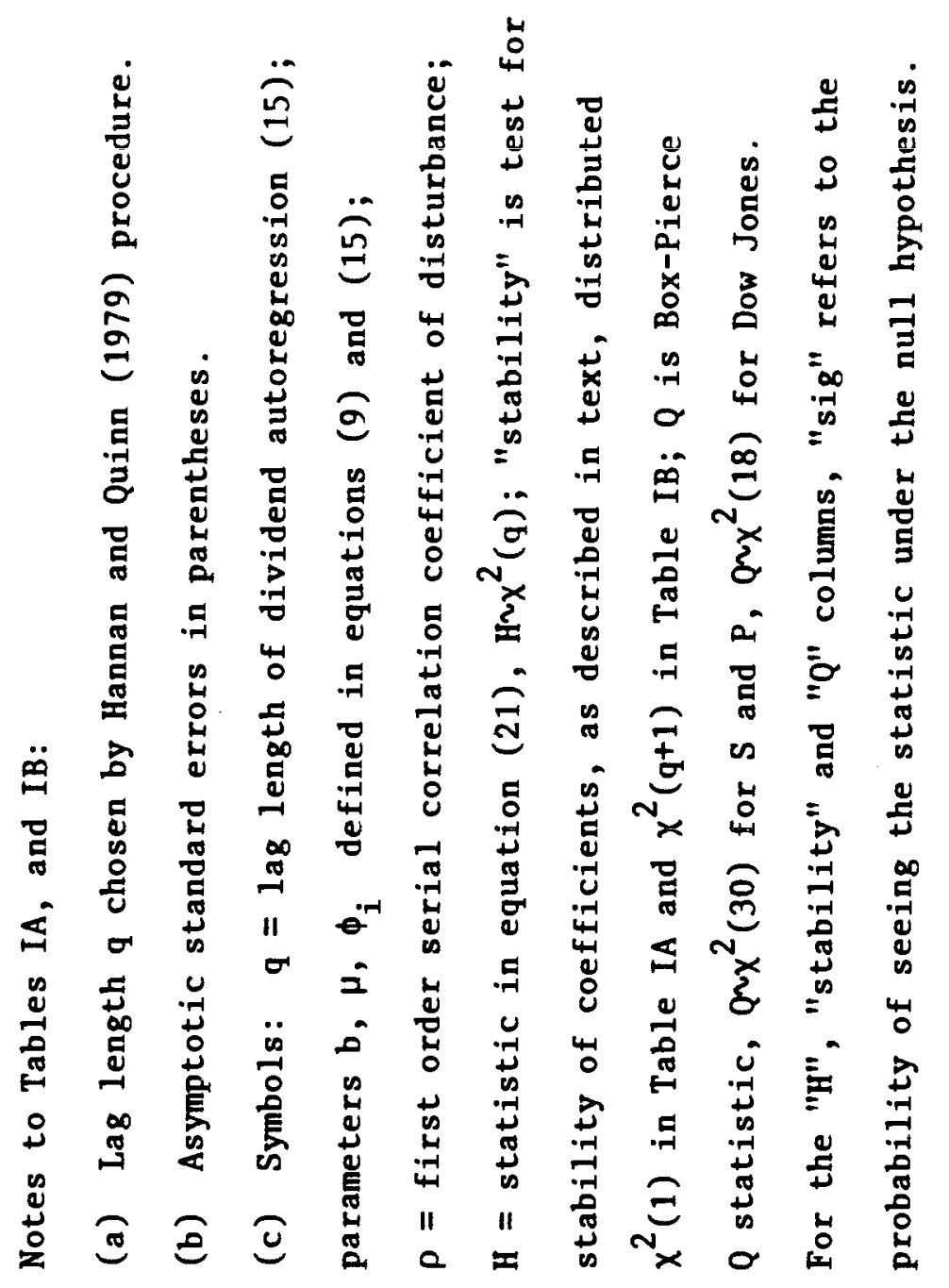




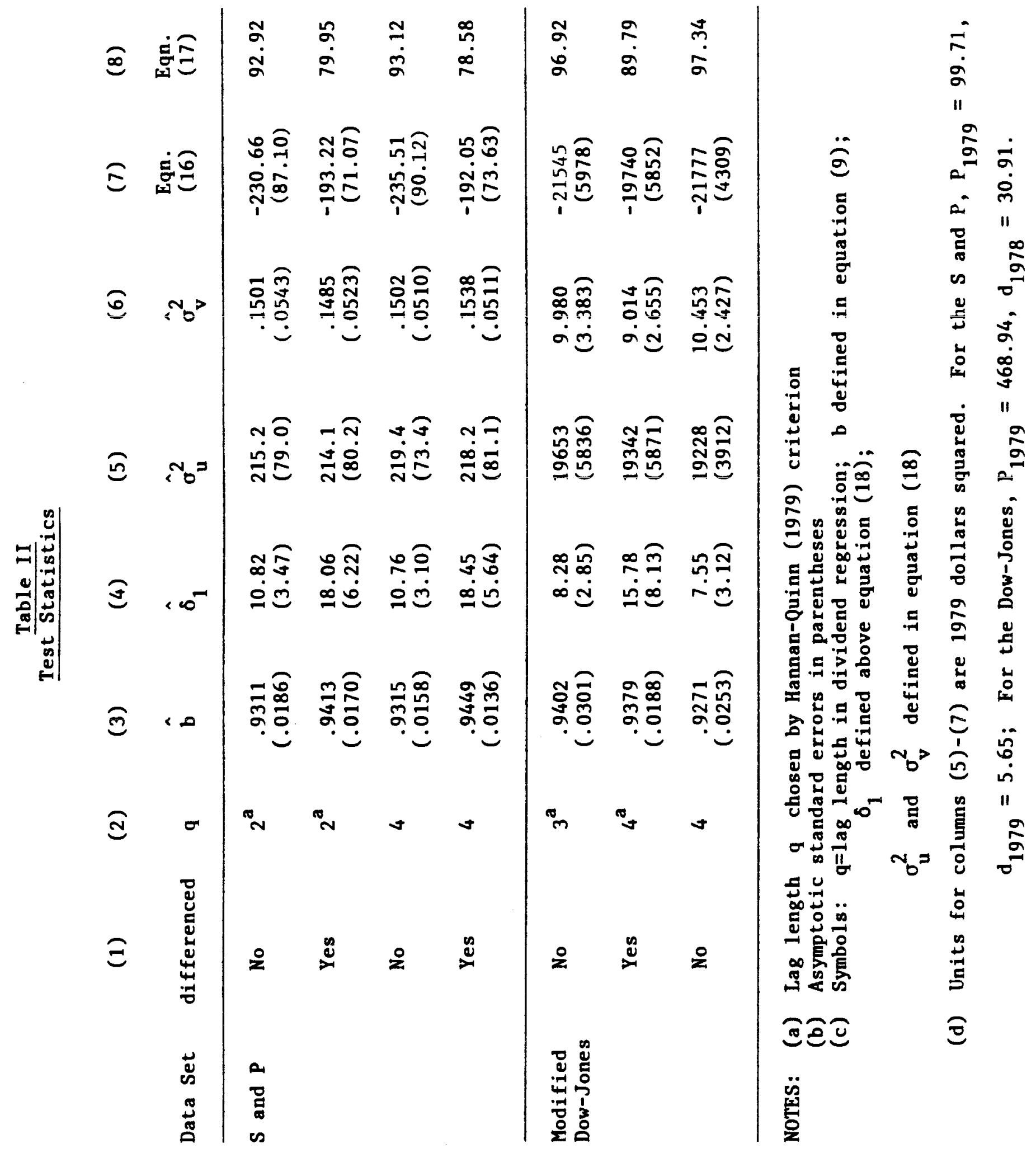


Table III A

Distribution of Equation (17) in Monte Carlo Experiment

$\begin{array}{lcccc}\text { Percentile } & \underline{5} & \underline{10} & \underline{50} & \frac{66}{0} \\ \text { Equation (17) } & 91.8 & 74.7 & 15.0 & 0\end{array}$

Table III B

Distribution of Equation (21) in Monte Carlo Experiment

$\begin{array}{lccccc}\text { Percentile } & \underline{5} & \underline{10} & \underline{50} & \underline{78} & \underline{90} \\ \text { Equation } & 25.26 & 22.29 & 10.80 & 5.99 & 3.07\end{array}$

Table IV A

Percentage Excess Price Variability

$\begin{array}{lccccccc}\underline{\alpha} & \frac{.5}{2} & \underline{1} & \underline{2} & \underline{3} & \frac{10}{25} & \frac{25}{20} & \underline{50} \\ \underline{\text { Equation (17) }} & 96.5 & 97.5 & 80.9 & 88.4 & 99.6 & 100.0 & 100.0\end{array}$

Table IV B

Minimum or Needed to Explain Excess Variability

$\begin{array}{lccccccc}\text { Data Set } & \text { S\&P } & \text { S\&P } & \text { S\&P } & \text { S\&P } & \text { DJ } & \text { DJ } & \text { DJ } \\ \text { Differenced } & \text { no } & \text { yes } & \text { no } & \text { yes } & \text { no } & \text { yes } & \text { no } \\ \text { Lags } & 2 & 2 & 4 & 4 & 3 & 4 & 4 \\ \text { Ir } & .146 & .222 & .146 & .201 & .127 & .176 & .169\end{array}$

